\title{
Spatially-Resolved Beam Current and Charge-State Distributions for the NEXT Ion Engine
}

\author{
James E. Pollard, Kevin D. Diamant, and Mark W. Crofton
}

The Aerospace Corporation, El Segundo, California

Michael J. Patterson and George C. Soulas

Glenn Research Center, Cleveland, Ohio 


\section{NASA STI Program . . . in Profile}

Since its founding, NASA has been dedicated to the advancement of aeronautics and space science. The NASA Scientific and Technical Information (STI) program plays a key part in helping NASA maintain this important role.

The NASA STI Program operates under the auspices of the Agency Chief Information Officer. It collects, organizes, provides for archiving, and disseminates NASA's STI. The NASA STI program provides access to the NASA Aeronautics and Space Database and its public interface, the NASA Technical Reports Server, thus providing one of the largest collections of aeronautical and space science STI in the world. Results are published in both non-NASA channels and by NASA in the NASA STI Report Series, which includes the following report types:

- TECHNICAL PUBLICATION. Reports of completed research or a major significant phase of research that present the results of NASA programs and include extensive data or theoretical analysis. Includes compilations of significant scientific and technical data and information deemed to be of continuing reference value. NASA counterpart of peer-reviewed formal professional papers but has less stringent limitations on manuscript length and extent of graphic presentations.

- TECHNICAL MEMORANDUM. Scientific and technical findings that are preliminary or of specialized interest, e.g., quick release reports, working papers, and bibliographies that contain minimal annotation. Does not contain extensive analysis.

- CONTRACTOR REPORT. Scientific and technical findings by NASA-sponsored contractors and grantees.
- CONFERENCE PUBLICATION. Collected papers from scientific and technical conferences, symposia, seminars, or other meetings sponsored or cosponsored by NASA.

- SPECIAL PUBLICATION. Scientific, technical, or historical information from NASA programs, projects, and missions, often concerned with subjects having substantial public interest.

- TECHNICAL TRANSLATION. Englishlanguage translations of foreign scientific and technical material pertinent to NASA's mission.

Specialized services also include creating custom thesauri, building customized databases, organizing and publishing research results.

For more information about the NASA STI program, see the following:

- Access the NASA STI program home page at http://www.sti.nasa.gov

- E-mail your question via the Internet to help@ sti.nasa.gov

- Fax your question to the NASA STI Help Desk at $443-757-5803$

- Telephone the NASA STI Help Desk at 443-757-5802

- Write to: NASA Center for AeroSpace Information (CASI) 7115 Standard Drive Hanover, MD 21076-1320 


\title{
Spatially-Resolved Beam Current and Charge-State Distributions for the NEXT Ion Engine
}

\author{
James E. Pollard, Kevin D. Diamant, and Mark W. Crofton
}

The Aerospace Corporation, El Segundo, California

Michael J. Patterson and George C. Soulas

Glenn Research Center, Cleveland, Ohio

Prepared for the

46th Joint Propulsion Conference and Exhibit

cosponsored by AIAA, ASME, SAE, and ASEE

Nashville, Tennessee, July 25-28, 2010

National Aeronautics and

Space Administration

Glenn Research Center

Cleveland, Ohio 44135 


\section{Acknowledgments}

Kevin McCormick of NASA Glenn Research Center built the electrical and propellant interfaces to the test facility and installed the thruster and its power and propellant systems. This work was supported under

The Aerospace Corporation’s Independent Research and Development Program.

This report contains preliminary findings, subject to revision as analysis proceeds.

Level of Review: This material has been technically reviewed by technical management.

Available from

NASA Center for Aerospace Information 7115 Standard Drive

Hanover, MD 21076-1320
National Technical Information Service 5301 Shawnee Road Alexandria, VA 22312

Available electronically at http://gltrs.grc.nasa.gov 


\title{
Spatially-Resolved Beam Current and Charge-State Distributions for the NEXT Ion Engine
}

\author{
James E. Pollard, Kevin D. Diamant, and Mark W. Crofton \\ The Aerospace Corporation \\ El Segundo, California 90245 \\ Michael J. Patterson and George C. Soulas \\ National Aeronautics and Space Administration \\ Glenn Research Center \\ Cleveland, Ohio 44135
}

\begin{abstract}
Plume characterization tests with the 36-cm NEXT ion engine are being performed at The Aerospace Corporation using engineering-model and prototype-model thrusters. We have examined the beam current density and xenon charge-state distribution as functions of position on the accel grid. To measure the current density ratio $j^{++} / j^{+}$, a collimated $\mathrm{E} \times \mathrm{B}$ probe was rotated through the plume with the probe oriented normal to the accel electrode surface at a distance of $82 \mathrm{~cm}$. The beam current density $j_{b}$ versus radial position was measured with a miniature planar probe at $3 \mathrm{~cm}$ from the accel. Combining the $j^{++} / j^{+}$and $j_{b}$ data yielded the ratio of total $\mathrm{Xe}^{+2}$ current to total $\mathrm{Xe}^{+1}$ current $\left(\mathrm{J}^{++} / J^{+}\right)$at forty operating points in the standard throttle table. The production of $\mathrm{Xe}^{+2}$ and $\mathrm{Xe}^{+3}$ was measured as a function of propellant utilization to support performance and lifetime predictions for an extended throttle table. The angular dependence of $j_{b}$ was measured at intermediate and far-field distances to assist with plume modeling and to evaluate the thrust loss due to beam divergence. Thrust correction factors were derived from the total doubles-to-singles current ratio and from the far-field divergence data.
\end{abstract}

\section{Nomenclature}

$\begin{array}{ll}F & \text { thrust } \\ I_{s p} & \text { specific impulse } \\ j^{+} & \text {position-dependent current density of } \mathrm{Xe}^{+1} \\ j^{++} & \text {position-dependent current density of } \mathrm{Xe}^{+2} \\ j^{+++} & \text {position-dependent current density of } \mathrm{Xe}^{+3} \\ J^{+} & \text {total } \mathrm{Xe}^{+1} \text { current } \\ J^{++} & \text {total } \mathrm{Xe}^{+2} \text { current } \\ J^{+++} & \text {total } \mathrm{Xe}^{+3} \text { current } \\ j_{b} & \text { position-dependent beam current density } \\ J_{b} & \text { total beam current } \\ P_{\text {in }} & \text { thruster input power (equals power processor output power) } \\ \mathrm{PP} & \text { planar probe } \\ \mathrm{RPA} & \text { retarding potential analyzer } \\ \mathrm{TL} & \text { throttle level } \\ V_{b} & \text { beam power supply voltage } \\ V_{d} & \text { discharge power supply voltage } \\ V_{g} & \text { neutralizer potential relative to chamber ground } \\ \alpha & \text { thrust correction factor for doubly-charged ions } \\ \beta & \text { thrust correction factor for beam divergence } \\ \gamma & \text { combined thrust correction factor }(=\alpha \beta) \\ \delta & \text { divergence angle of } j_{b} \text { vector relative to ion optics centerline }\end{array}$


$\eta_{e} \quad$ thruster electrical efficiency (beam power / thruster input power)

$\eta_{t} \quad$ overall thruster efficiency

$\eta_{u} \quad$ total propellant utilization efficiency

$\eta_{u d} \quad$ propellant utilization efficiency for main discharge

$\theta \quad$ probe angle relative to ion optics centerline, vertex at center of exit plane

$\rho \quad$ doubles current density ratio, $j^{++} / j^{+}$

$\sigma \quad$ triples current density ratio, $j^{+++} /\left(j^{+}+j^{++}\right)$

$\psi \quad$ probe angle relative to ion optics centerline, vertex at turntable axis of rotation

$\zeta \quad$ probe angle relative to ion optics centerline, vertex at accel grid edge

\subsection{Introduction}

NASA's Evolutionary Xenon Thruster (NEXT) is engineered to be extremely flexible in terms of input power and specific impulse, while maintaining acceptable efficiency, and embodies a number of advances over previous ion engine systems (Refs. 1 to 6 ). NEXT as an integrated project is comprised of the development of an advanced xenon ion thruster, a power processor unit, a xenon feed system, a gimbal, and the control algorithms for system operation. Some of the operating characteristics of the thruster are being examined in a laboratory test program conducted at The Aerospace Corporation (Ref. 7). The work is performed under the umbrella of a Space Act Agreement, with NASA participation in readying and operating the hardware being tested.

Mission application studies and long-duration life-testing of NEXT have focused on the standard throttle levels listed in Table 1. Potential enhancements in performance and service life relative to this baseline have been investigated analytically based on available laboratory data, showing that increased propellant utilization efficiency would improve the specific impulse and overall thruster efficiency (Refs. 8 and 9). Higher propellant efficiency leads to a greater fraction of doubly-charged xenon in the main discharge, which causes (1) a small reduction in thrust relative to the performance if only $\mathrm{Xe}^{+1}$ is present, and (2) an increase in the wear rate of the screen electrode and cathode keeper. Nevertheless, higher propellant efficiency is predicted to increase NEXT service life by suppressing the wear rate of the accel electrode by charge-exchange ions. In this paper we revisit the laboratory measurements that support predictions of thruster performance and service life (Refs. 10 and 11). New test results include the $\mathrm{Xe}^{+2}$ and $\mathrm{Xe}^{+3}$ current densities versus radial position on the accel electrode for the entire throttle table and versus propellant utilization at selected operating points. We measured the beam current density versus radial position very close to the accel to supplement the charge-state data and to allow a comparison of beamlet profiles with theoretical modeling. Finally, beam current density scans were performed at intermediate and far-field distances to provide input for plume effects modeling and to evaluate the thrust correction factor associated with beam divergence. In a separate publication we present direct mechanical thrust measurements for NEXT and compare them with the corrected thrust derived from electrical parameters (Ref. 12).

TABLE 1.-BEAM CURRENT, BEAM SUPPLY VOLTAGE, DISCHARGE PROPELLANT EFFICIENCY

\begin{tabular}{|c|c|c|c|c|c|c|c|c|c|c|c|c|}
\hline \multirow{2}{*}{$\begin{array}{c}J_{b} \\
(\mathrm{~A})\end{array}$} & \multicolumn{9}{|c|}{$V_{b}$} \\
& 1800 & 1567 & 1396 & 1179 & 1021 & 936 & 850 & 679 & 650 & 400 & 300 & 275 \\
\hline 3.52 & TL40 & TL39 & TL38 & TL37 & & & & & & & & \\
\hline 3.10 & TL36 & TL35 & TL34 & TL33 & & & & & & & & \\
\hline 2.70 & TL32 & TL31 & TL30 & TL29 & TL28 & & $\eta_{\text {ud }}=$ & $87 \%$ & $93 \%$ & $89 \%$ & & \\
\hline 2.35 & TL27 & TL26 & TL25 & TL24 & TL23 & & & & & & & \\
\hline 2.00 & TL22 & TL21 & TL20 & TL19 & TL18 & & & & & & & \\
\hline 1.60 & TL17 & TL16 & TL15 & TL14 & TL13 & & & & & & & \\
\hline 1.20 & TL12 & TL11 & TL10 & TL09 & TL08 & TL07 & TL06 & TL05 & TL04 & TL03 & TL02 & \\
\hline 1.00 & & & & & & & & & & & & TL01 \\
\hline
\end{tabular}




\subsection{Test Setup}

Measurements were performed in a 2.4-m diameter by 9.8-m long cryopumped vacuum chamber with the thruster oriented along the chamber centerline. Two re-entrant pumps were on the end-dome behind the thruster, two more re-entrant pumps were in the beam dump region, and four 1.3-m cryotubs were mounted on the cylindrical wall of the tank adjacent to the thruster. The base pressure with no gas load was less than $1 \times 10^{-7}$ torr, with 90 percent of the residual gas being water vapor, and the remainder being air and hydrocarbons. The beam dump was lined with carbon composite sheets and flexible graphite to minimize the yield of sputtered material. Lab power supplies and a lab propellant feed system were used to operate the EM4 engineering model thruster and the PM1R prototype model (Ref. 6) thruster at the beam currents and voltages listed in Table 1 . Also listed are the values for the discharge propellant efficiency $\eta_{u d}$, as tested in this facility. Background pressure was measured by an ionization gauge located on the tank wall adjacent to the thruster. With an 1800-V, 3.52-A beam (TL40) the xenon pressure was $3.6 \times 10^{-6}$ torr, applying the correction factor of 0.348 specified by the gauge manufacturer for xenon relative to nitrogen. The effective pumping speed for this condition was $2.1 \times 10^{5}$ liter/s.

A key objective of the test was to measure charge-state distribution versus position on the accel grid, but doing this directly with an intrusive probe might perturb the plume excessively. Instead, we used a spatially-resolving $\mathrm{E} \times \mathrm{B}$ probe at a downstream location, in combination with a miniature planar probe to measure beam current density versus radial position very close to the grid. Figure 1 shows the arrangement for scanning the probes at a constant distance from the spherical accel surface with the viewing direction normal to the surface. The probe arm was driven by a turntable located behind the thruster so that the axis of rotation coincided with the center of curvature of the grid. Four posts supporting the thruster were spaced far enough apart to allow the probe to scan across the full width of the accel in the thruster mid-plane. Prior to adopting this setup, we installed a different mechanical arrangement to confirm that the $\mathrm{E} \times \mathrm{B}$ signal was maximized in the grid-normal direction at all radial positions, as expected for the compensation design of the ion optics. The setup in Figure 1 differed from what was used in previous measurements of the NEXT charge-state distribution (Refs. 13 and 14), which were made on thruster centerline at 4.2 and $7.6 \mathrm{~m}$ downstream, or in a radial traverse at $1.5 \mathrm{~m}$ downstream with the probe in a fixed orientation parallel to the centerline. In earlier studies with a 30-cm ion engine and with the NSTAR thruster, the doubles-to-singles ratio was measured on centerline at $15 \mathrm{~cm}$ from the accel (Ref. 15) or in the far-field using a fixed probe orientation (Ref. 16).

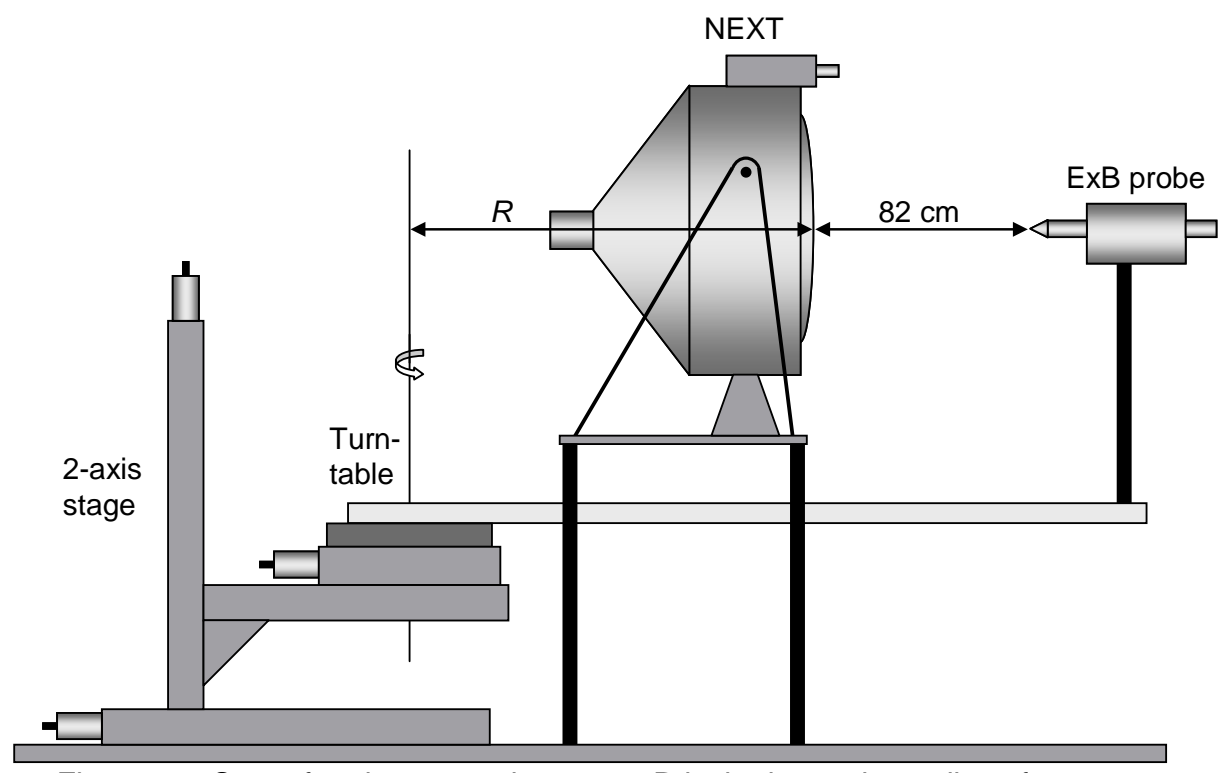

Figure 1.-Setup for plume angular scans. $\mathrm{R}$ is the ion optics radius of curvature. 


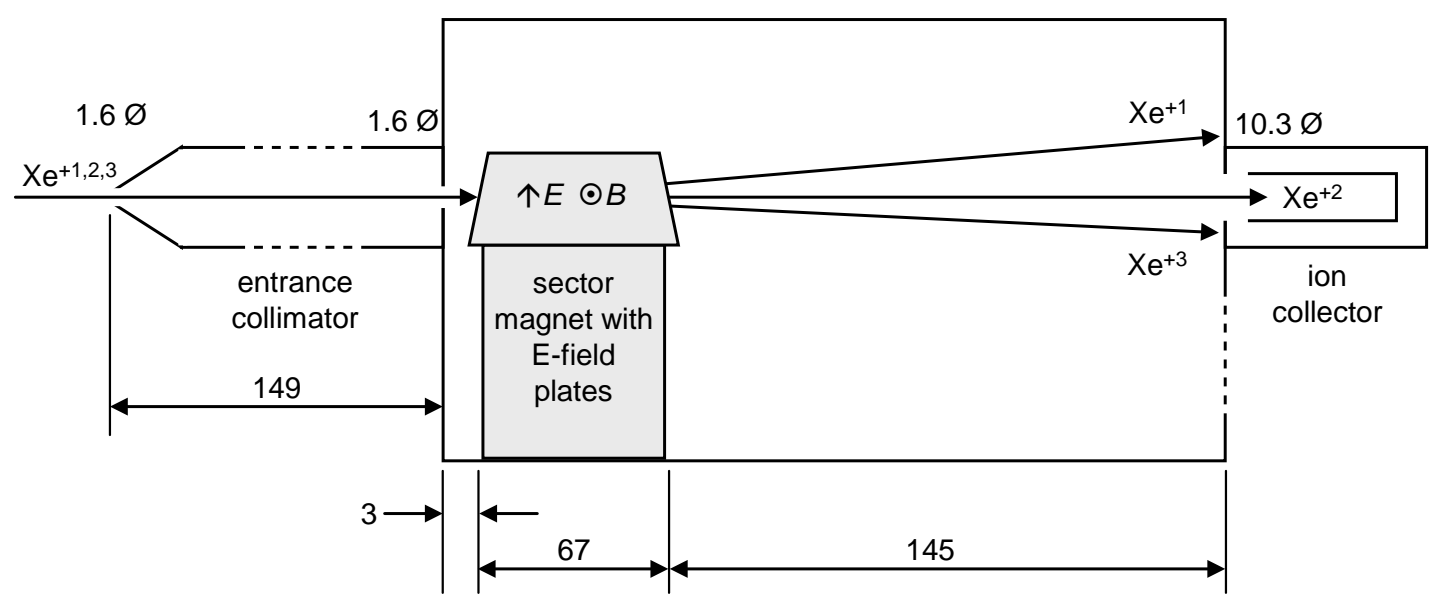

Figure 2.-Schematic of $\mathrm{E} \times \mathrm{B}$ charge-state analyzer with dimensions in $\mathrm{mm}$.

With a gridded ion source the particle velocity scales as the square-root of the charge-to-mass ratio. Figure 2 shows the dimensions of an $\mathrm{E} \times \mathrm{B}$ Wien filter for analyzing plume ions as a function of velocity to separate the charge states. For the case of orthogonal electric and magnetic fields, a charged particle with a velocity vector perpendicular to the fields is transmitted without deflection if the magnitude of its velocity equals $E / B$ (Ref. 17). Given the narrow distribution of the kinetic-energy-to-charge ratio, and given that xenon was the only significant constituent of the beam, the charge-state resolution was determined mainly by the degree of collimation upstream of the fields and by the size of the ion collector aperture. The entrance collimator consisted of a conical skimmer machined from pyrolytic graphite followed by a stainless steel aperture, both having 1.6-mm diameter. A horseshoe-type sector magnet (0.186 T, 13-mm gap), originally part of a commercial mass spectrometer, was fitted with a pair of pyrolytic graphite electrode plates (7-mm gap) to establish the electric field. In order to have the desired flat-topped peaks when measuring the ion current versus velocity, the exit aperture diameter $(10.3 \mathrm{~mm})$ was larger than the diameter of the separated beamlets (ca. $6 \mathrm{~mm})$. This insured that the peak-height ratios accurately represented the entire sample of ions entering the $\mathrm{E} \times \mathrm{B}$ probe. The collector cup was deep enough to prevent the escape of incoming ions and secondary electrons, and it was biased using a battery at $-7 \mathrm{~V}$ relative to the grounded housing to suppress the electron background that leaked in from the thruster plume. Pump-out holes covered with fine mesh were provided in the entrance collimator and in the main housing to ensure that the dynamic pressure from neutralized beam ions $\left(<3 \times 10^{-7}\right.$ torr in the collimator) was much less than the static pressure due to xenon background gas. The electric field was swept using a Keithley 2410 SourceMeter connected to a voltage divider that established potentials of equal magnitude on the lower $(+)$ electrode and the upper $(-)$ electrode. The magnet poles were at ground potential. Collector current was recorded by a Keithley 6485 picoammeter as a function of ion velocity, probe angle, and probe axial position on centerline. Figure 3 shows the test facility configured with the thruster and $\mathrm{E} \times \mathrm{B}$ probe.

Angular scans were performed with the $\mathrm{E} \times \mathrm{B}$ entrance aperture at $82 \mathrm{~cm}$ from the spherical surface of the accel grid. Prior to pump-down the probe was aligned by temporarily detaching the collector housing and aiming a penlight back through the probe to produce a spot of light on the grid, while adjusting the turntable offset and probe azimuth to align the light with the grid edges and with the central grid hole. The penlight showed that the $\mathrm{E} \times \mathrm{B}$ viewing spot on the accel grid was about 8-mm diameter, which encompassed 13 to 14 accel holes and corresponded to an increment of $0.6^{\circ}$ in the angular scans. We also used an alignment fixture attached to the ion optics that directed a laser beam downstream along the ion optics centerline. The location of the collimated $\mathrm{E} \times \mathrm{B}$ probe meant that only ions with velocity vectors normal to the grid surface were detected. Assuming the $j^{++} / j^{+}$ratio was uniform for all ions extracted through the plasma sheath of a given screen grid hole, the ratio measured downstream for that grid hole was independent of probe angle relative to the grid surface, because the path of an ion through the grids 
was independent of charge state. Therefore, the $j^{++} / j^{+}$ratio measured at $82 \mathrm{~cm}$ in grid-normal orientation was the same as what would be measured at the accel grid when averaged over the diameter of the viewing spot. This reasoning ignores the effect of charge-exchange collisions in the downstream region, for which we applied a correction based on axial scans with the $\mathrm{E} \times \mathrm{B}$ probe on thruster centerline (see Section 3.1).

Beam current density varied as a function of position on the grid, as did the fraction of ions having trajectories normal to the grid surface. The normal-current fraction was expected to decrease with decreasing beamlet current, meaning that beamlets produced near the grid edge were more divergent than those produced near centerline. Therefore the current density measured by the $\mathrm{E} \times \mathrm{B}$ probe decreased faster toward the grid edge than the actual profile of $j_{b}$ at the accel. Because the probe measured $j^{++} / j^{+}$locally, we needed also to measure $j_{b}$ locally (i.e., close to the accel) for correctly determining the total current ratio $J^{++} / J^{+}$. Hence the $\mathrm{E} \times \mathrm{B}$ scans were supplemented by measurements with a miniature planar probe, again using the rotating arm to scan in a grid-normal orientation at constant distance from the accel (see Fig. 4). The collector was a stainless steel wire, viewed end-on, with a diameter of $0.4 \mathrm{~mm}$. The wire was jacketed in a 0.8-mm OD alumina tube, within a 1.1-mm OD stainless steel tube that served as a guard ring, and finally within a 2.5-mm OD alumina tube that extended back to a connectorized housing. Current versus applied voltage was measured with two Keithley 2410 SourceMeters, one for the collector and one for the guard. Data were recorded at $3 \mathrm{~cm}$ from the accel by stepping the miniature planar probe

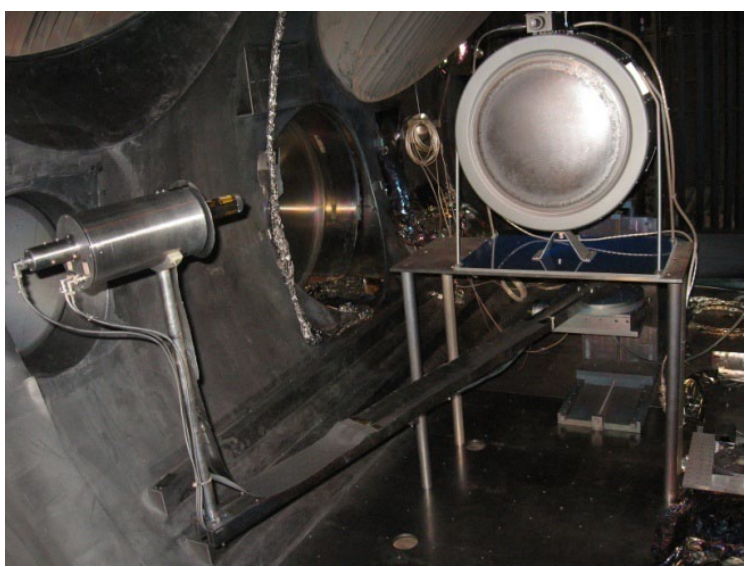

Figure 3.-ExB probe on rotating arm at $82 \mathrm{~cm}$ from the accel grid of the PM1R.

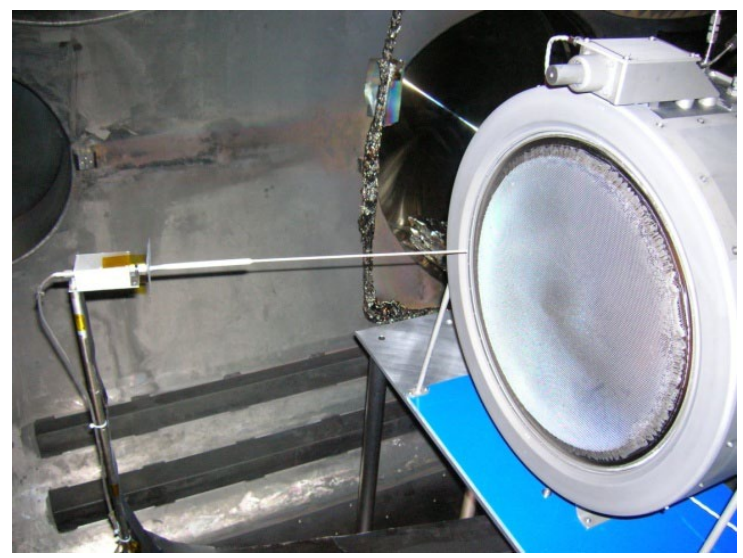

Figure 4.-Miniature planar probe at $3 \mathrm{~cm}$ from accel grid of the PM1R. 


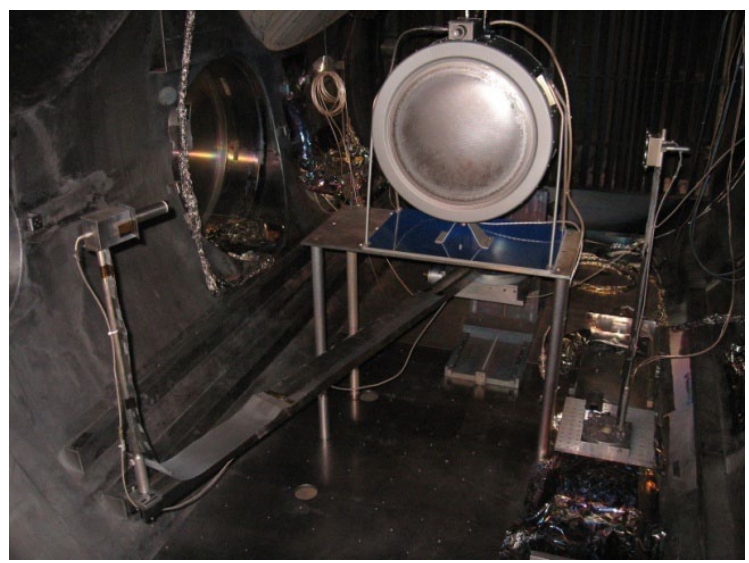

Figure 5.-Planar probe on rotating arm at $85 \mathrm{~cm}$ from the accel grid of the PM1R, and RPA on axial translator with turntable for adjusting the viewing direction.

through a set of 25 positions corresponding to the locations of the viewing spot for the $\mathrm{E} \times \mathrm{B}$ probe. For measurements of beamlet profiles at 0.5 to $2.0 \mathrm{~cm}$ from the accel, the probe was biased at $-20 \mathrm{~V}$ and moved in a continuous sweep while the SourceMeter stored data at $18.5 \mathrm{~Hz}$ until its internal buffer was filled (2500 readings). Although the nominal area of the collector was $1.3 \times 10^{-3} \mathrm{~cm}^{2}$, normalizing the scans to the known total beam current $J_{b}$ implied that the effective area was 1.5 to $2.0 \times 10^{-3} \mathrm{~cm}^{2}$ with the collector and guard ring biased at $-20 \mathrm{~V}$ relative to ground. Probe I-V curves did not always show saturation of the ion current versus bias potential, so we relied on normalizing to $J_{b}$ when attaching absolute units to the ion signal. However, only relative units for $j_{b}$ were needed to process the charge-state data. Modifying the probe design to narrow the dimensional tolerances and to extend the size of the guard ring might improve the ion saturation behavior.

Measurements of beam current density versus angle were made at $85 \mathrm{~cm}$ from the accel for comparison with $\mathrm{E} \times \mathrm{B}$ data taken at approximately the same distance. In this case $j_{b}$ was measured with a conventional guard-ring planar probe using the rotating arm to scan in a grid-normal orientation at a constant distance of $85 \mathrm{~cm}$ (see Fig. 5). The collector diameter was $1.27 \mathrm{~cm}$, and the guard ring outer diameter was $2.54 \mathrm{~cm}$. At each angle the I-V curve showed saturation of the ion current with collector and guard potentials of $-20 \mathrm{~V}$. To quantify the energetic ion flux at high divergence angles, a retarding potential analyzer (Ref. 18) was mounted on an axial translation stage at $51 \mathrm{~cm}$ radial distance from the thruster centerline (see Fig. 5). At the interface between the RPA and the axial stage there was a small turntable that adjusted the viewing angle of the probe as a function of axial position. Calibration of the RPA grid transmission as a function of beam energy was by comparison with a gridded flux probe having a known sensitivity (Ref. 18).

To evaluate the thrust loss due to beam divergence, we measured $j_{b}$ versus angle using the planar probe at $273 \mathrm{~cm}$ and the RPA at $281 \mathrm{~cm}$ from the accel in grid-normal orientation. For these far-field scans the thruster was pivoted by $12^{\circ}$ away from chamber centerline to expand the angular range, and the probe axis of rotation coincided with the center of curvature of the ion optics, as in Figure 1. The two farfield probes were mounted together on the rotating arm and were displaced above and below the thruster mid-plane by +3 and $-3 \mathrm{~cm}$. For all other data reported in this paper the probes were confined to the thruster mid-plane. 
TL33, PM1R, $96 \%$ utilization, $+4.8 \mathrm{~cm}$ radial on accel

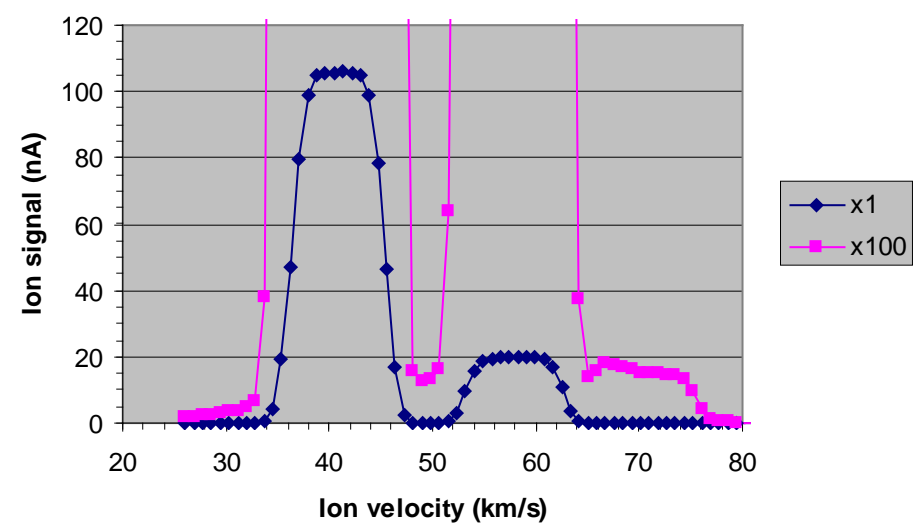

Figure 6.-ExB data at high utilization efficiency showing peaks for $\mathrm{Xe}^{+1}(40 \mathrm{~km} / \mathrm{s}), \mathrm{Xe}^{+2}(58 \mathrm{~km} / \mathrm{s})$, and $\mathrm{Xe}^{+3}(70 \mathrm{~km} / \mathrm{s})$. The duration of the sweep was $12 \mathrm{~s}$.

TL01, PM1R, $88 \%$ utilization, $+7.9 \mathrm{~cm}$ radial on accel

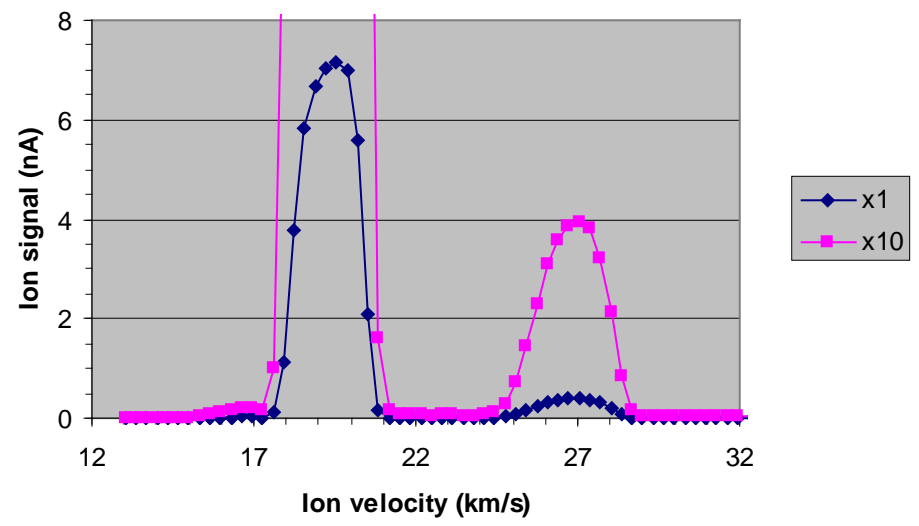

Figure 7.-ExB data at low beam voltage showing peaks for $\mathrm{Xe}^{+1}$ $(20 \mathrm{~km} / \mathrm{s})$ and $\mathrm{Xe}^{+2}(27 \mathrm{~km} / \mathrm{s})$.

\subsection{Results}

\subsection{ExB Probe Performance}

Figure 6 illustrates charge-state separation with the $\mathrm{E} \times \mathrm{B}$ probe for one of the highest levels of multiple ionization among the operating points that we examined. The beam voltage and current corresponded to TL33 in Table 1, but the discharge utilization efficiency was increased to 96 percent, which gave a current density ratio for $\mathrm{Xe}^{+1}, \mathrm{Xe}^{+2}$, and $\mathrm{Xe}^{+3}$ of 100: 19: and 0.14 percent. Peak shapes were nearly flat-topped, as intended for this choice of aperture diameters, so that the full intensity could be measured at the center of each peak. For TL04 to TL40 the shapes were similar to what is shown Figure 6, while for the lowest beam voltages (TL01 to TL03) a narrower shape was observed, probably because the beam inside the probe was displaced from the center of the exit aperture by stray fields. An example for TL01 at $275 \mathrm{~V}$ is shown in Figure 7. $\mathrm{E} \times \mathrm{B}$ voltage scans were performed at 25 angular positions from $-15.1^{\circ}$ to $+15.1^{\circ}$, corresponding to radial distances on the accel of $-18.5 \mathrm{~cm}$ to $+18.5 \mathrm{~cm}$ in the thruster mid-plane, where a positive distance was to the right of the neutralizer if one were facing the ion optics. The time needed to complete an angular scan was $6 \mathrm{~min}$. Peak heights were taken to be the maximum value in the flat-topped region. Figure 8 shows an example of the radial dependence of the current 
densities at high utilization efficiency. The departure from axisymmetry seen in E×B data for the PM1R thruster was also evident in scans with planar probe at $3 \mathrm{~cm}$ from the accel (see Section 3.3).

Charge-exchange collisions between beam ions and neutral xenon caused the measured $j^{++} / j^{+}$to vary with distance from the accel grid. The relevant reactions were studied as a function of collision energy by Miller, et al (Ref. 19). Between 1800 and $600 \mathrm{eV}$ (TL40 to TL04) the total cross sections are

$$
\begin{aligned}
& \mathrm{Xe}^{+1}+\mathrm{Xe} \rightarrow \mathrm{Xe}+\mathrm{Xe}^{+1}, 43 \text { to } 50 \AA^{2} \\
& \mathrm{Xe}^{+2}+\mathrm{Xe} \rightarrow \mathrm{Xe}+\mathrm{Xe}^{+2}, 12 \text { to } 14 \AA^{2} \\
& \mathrm{Xe}^{+2}+\mathrm{Xe} \rightarrow \mathrm{Xe}^{+1}+\mathrm{Xe}^{+1}, 1 \text { to } 3 \AA^{2}
\end{aligned}
$$

Therefore, $\mathrm{Xe}^{+1}$ at the beam energy was more likely to be lost by conversion to neutral Xe than was $\mathrm{Xe}^{+2}$. The third reaction listed above produces a pair of singly-charged ions, one of which nominally retains the velocity of the reactant $\mathrm{Xe}^{+2}$ ion. However, this contribution to the $j^{++}$signal from the $\mathrm{E} \times \mathrm{B}$ probe was minimal because (1) the reaction is less probable than the other charge-exchange processes, (2) the product ion carries one rather than two units of charge, and (3) the small cross section implies a non-zero momentum exchange between reactants which would deflect the product ion from the grid-normal direction.

Figure 9 shows the axial dependence of $j^{+}, j^{++}$, and $j^{++} / j^{+}$measured with the ExB probe at TL33 to illustrate the depletion of $\mathrm{Xe}^{+1}$ relative to $\mathrm{Xe}^{+2}$ with increasing distance. The ratio $j^{++} / j^{+}$at TL33 and other throttle levels approximated a linear function of distance over this range. If one knew the spatial dependence of xenon neutral density in the chamber, it would be possible to derive an analytic correction for the $\mathrm{E} \times \mathrm{B}$ results. Without neutral density data, an alternative is to characterize the axial dependence of $j^{++} / j^{+}$for all probe angles at every throttle level and to extrapolate back to the accel grid. Constraints of time and the mechanical setup limited us to measuring the axial dependence of $j^{++} / j^{+}$for a subset of throttle levels with the probe on thruster centerline. Axial scans were made as a function of beam current at $1179 \mathrm{~V}$, namely TL09, 14, 19, 24, 29, 33, and 37. The data were extrapolated linearly to zero axial distance to determine the correction multiplier for $j^{++} / j^{+}$versus beam current, which was then applied to the $\mathrm{E} \times \mathrm{B}$ angular data at all beam voltages and probe angles. The multiplier, which was applied to $j^{+++} / j^{+}$ as well as $j^{++} / j^{+}$, ranged from 0.99 to 0.93 for beam currents between 1.2 and 3.5 A. Within the nominal fluctuation of thruster operating parameters we were not able to detect a variation in the correction multiplier as a function of beam voltage.

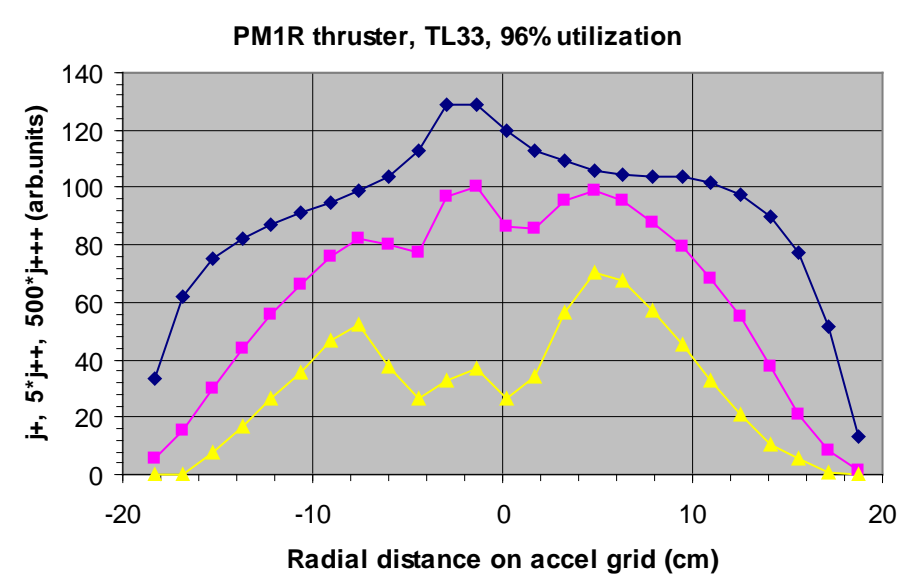

Figure 8.- Radial dependence of $\mathrm{Xe}^{+1}$ (blue), $\mathrm{Xe}^{+-2}$ ( $\mathrm{x} 5$, magenta), and $\mathrm{Xe}^{+3}(\times 500$, yellow) signals at high utilization efficiency. 

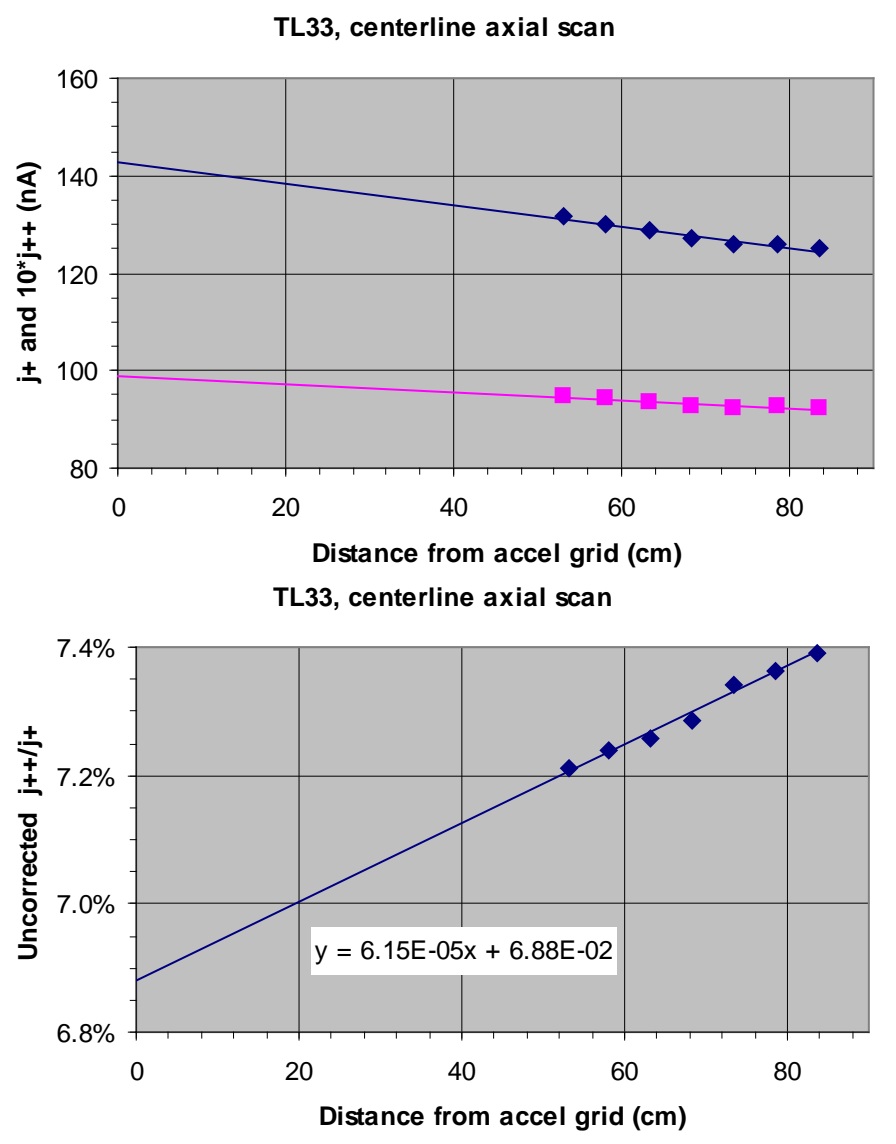

Figure 9.-Centerline current densities versus axial distance measured with the $\mathrm{E} \times \mathrm{B}$ probe.

\subsection{Radial Dependence of $j^{++} / j^{+}$}

For each of the 40 throttle levels in Table 1, E×B data were measured at 25 probe positions in the thruster mid-plane spanning the width of the perforated region of the accel grid. Figure 10 is a representation of this data set for the PM1R thruster, grouped into charts by beam current and corrected for the depletion of $\mathrm{Xe}^{+1}$ relative to $\mathrm{Xe}^{+2}$ with axial distance. It was anticipated that the maximum doubles-to-singles ratio would occur on thruster centerline, but this proved not to be the case. Instead, the centerline was typically a local minimum, with the maximum $j^{++} / j^{+}$occurring at radial distances of 5 to $8 \mathrm{~cm}$ on either side of centerline. Presumably this would appear as an annular maximum if the entire accel grid were interrogated with the $\mathrm{E} \times \mathrm{B}$ probe. The radial dependence of $j^{++} / j^{+}$is an indicator for electron temperature upstream of the screen electrode, in response to the radial variation of propellant density and of magnetic field. The data in Figure 10 were used to calculate the total current ratio $J^{++} / J^{+}$under the assumption that $j^{++} / j^{+}$in the mid-plane was representative of the entire beam (see Section 3.4). 

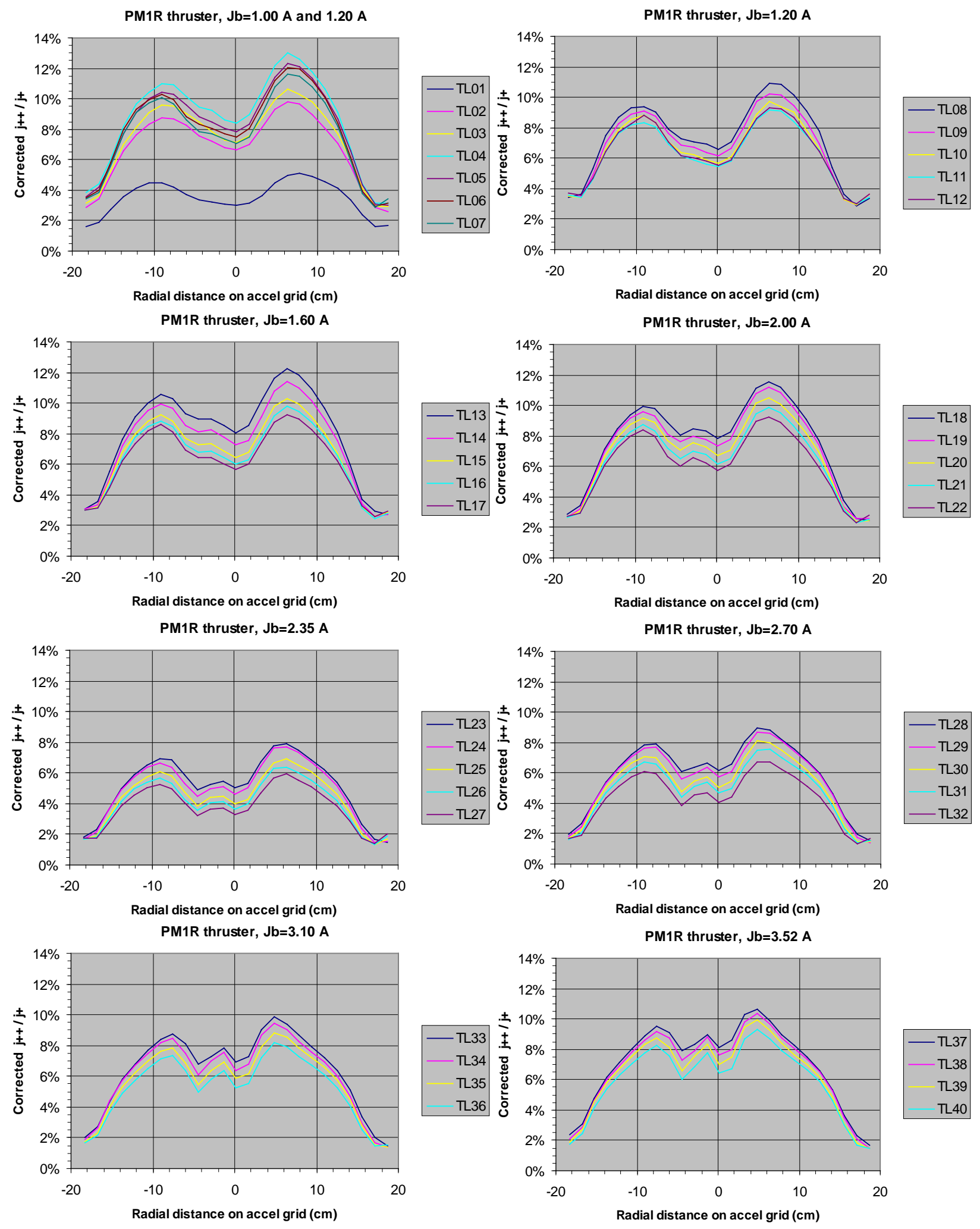

Figure 10.-Ratio of $\mathrm{Xe}^{+2}$ to $\mathrm{Xe}^{+1}$ current density $j^{++} / j^{+}$versus radial distance for the PM1R. 
PM1R thruster, $3 \mathrm{~cm}$ from accel, Vb=275-936 V
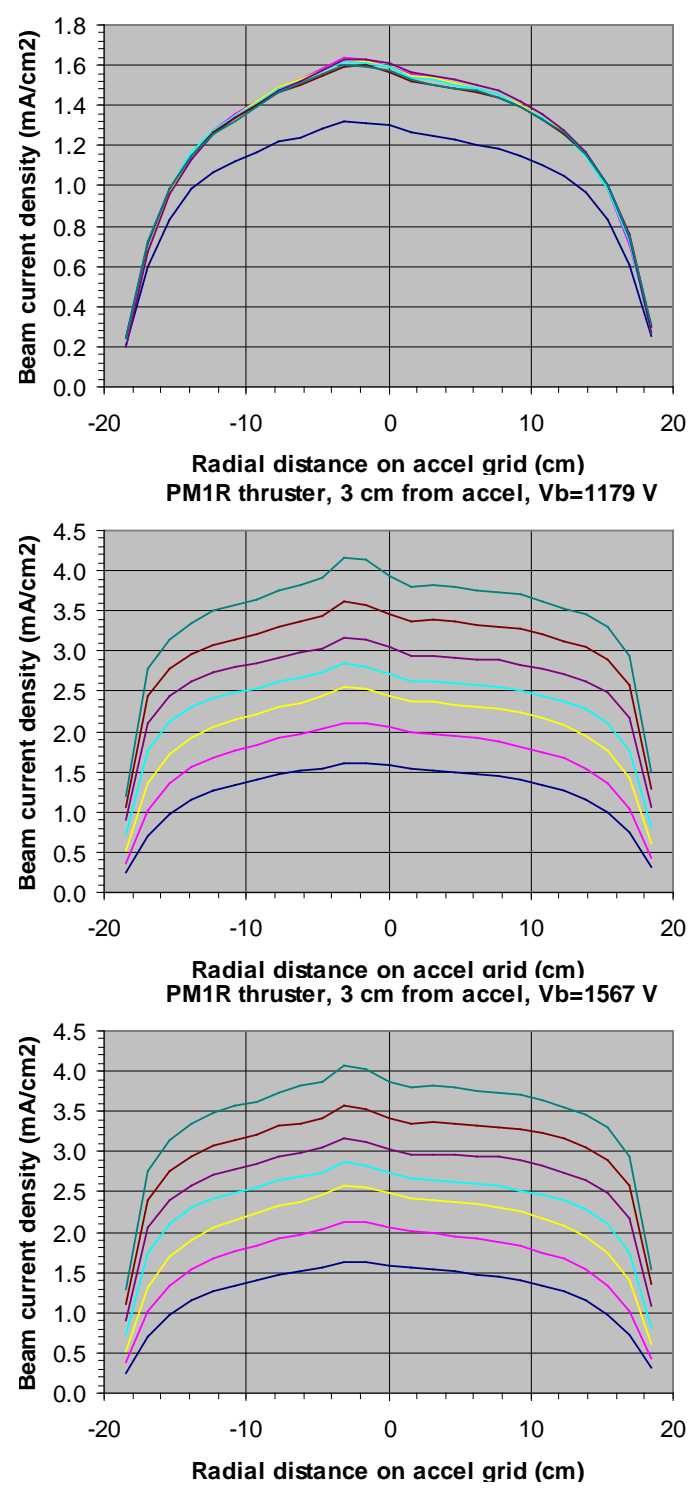

20
PM1R thruster, $3 \mathrm{~cm}$ from accel, $\mathrm{Vb}=1021 \mathrm{~V}$
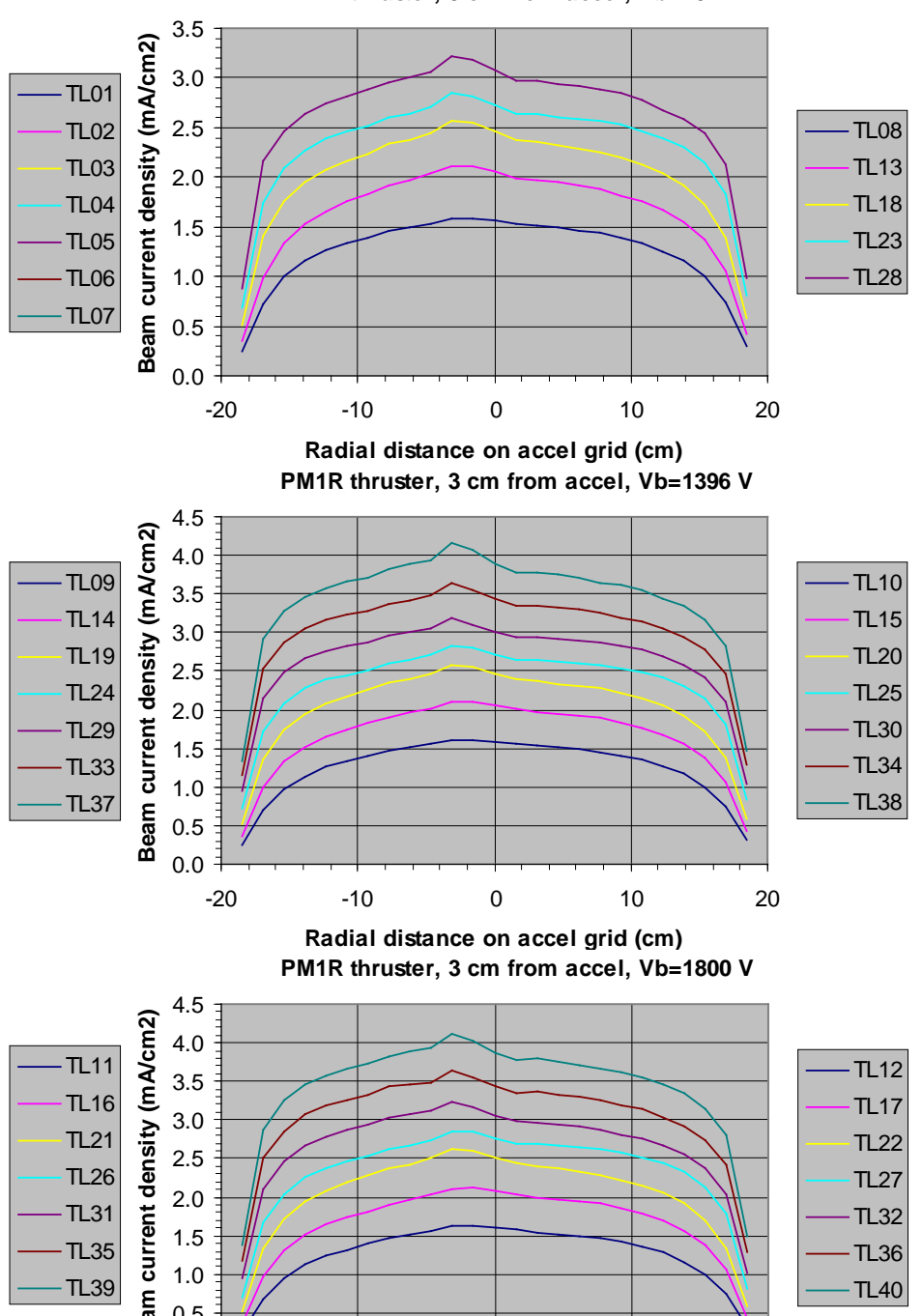

Radial distance on accel grid (cm) PM1R thruster, $3 \mathrm{~cm}$ from accel, $\mathrm{Vb}=1800 \mathrm{~V}$

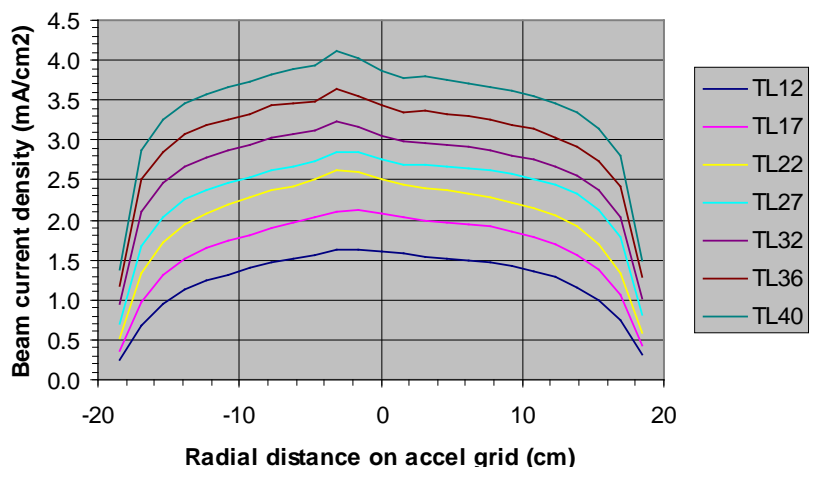

Figure 11.-Beam current density $j_{b}$ versus radial distance at $3 \mathrm{~cm}$ from the accel for the PM1R.

\subsection{Radial Dependence of $\boldsymbol{j}_{b}$ at $\mathbf{3} \mathbf{~ c m}$}

For each of the 40 throttle levels in Table 1, miniature planar probe data were recorded at 25 positions in the thruster mid-plane at $3 \mathrm{~cm}$ from the accel grid. Figure 11 is a representation of this data set for the PM1R thruster, grouped into charts by beam voltage. Each curve is normalized to the known total beam current $J_{b}$ with the collector area as a free parameter (see Section 2.0). A distance of $3 \mathrm{~cm}$ from the accel was far enough for the individual beamlets to merge, which was necessary when using $j_{b}$ data together with current densities measured by the $\mathrm{E} \times \mathrm{B}$ probe to derive the total current ratios for $\mathrm{Xe}^{+1}, \mathrm{Xe}^{+2}$, and $\mathrm{Xe}^{+3}$. Previously, the radial dependence of $j_{b}$ in the thruster mid-plane was measured in the EM3 LongDuration Test (Ref. 5) using linear traverses at $2 \mathrm{~cm}$ downstream from the geometric center of the accel grid. Our Figure 11 is in fair agreement with the EM3 data at $1800 \mathrm{~V}$, with differences that are attributable to unit variation (PM1R versus EM3) and to the different methods for scanning the probes (constant $3 \mathrm{~cm}$ from accel versus linear traverse). The three units (EM3, EM4, PM1R) all showed an offcenterline bump on the otherwise smooth radial profile of $j_{b}$ at each TL. The origin of this feature is 
unknown. For the PM1R the location of the bump ( $-3 \mathrm{~cm}$ radial distance) coincided with a local

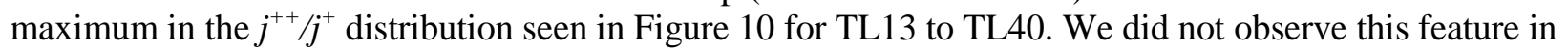
$j_{b}$ profiles at $85 \mathrm{~cm}$ from the accel (see Section 3.5). It would be of interest to measure the spatial dependence of $j_{b}$ over the entire accel grid to better understand the non-axisymmetric behavior. Beam flatness is defined as the ratio of average-to-peak beam current densities, where the average $j_{b}$ equals total beam current $J_{b}$ divided by perforated area $\left(1071 \mathrm{~cm}^{2}\right)$. For the PM1R mid-plane data in Figure 11, flatness was in the range of 0.69 to 0.81 and increased with total beam current in a roughly linear relation $\left(=0.646+0.047 J_{b}\right)$. There was no uniform trend in flatness versus beam voltage.

\subsection{Multiply-Charged Ion Production Versus Throttle Level and Propellant Utilization}

The results from the previous sections were used for calculating total current ratios, as explained in Appendix A. Figure 12 shows the discharge potential $V_{d}$ and the doubles ratio $J^{++} / J^{+}$versus throttle level for the EM4 and PM1R thrusters. As noted in Table 1, the discharge propellant utilization for standard throttle conditions was 87 percent at TL01, 93 percent at TL02 to TL22, and 89 percent at TL23 to TL40. When the $\mathrm{E} \times \mathrm{B}$ data were recorded the discharge voltage was nearly the same for the two thrusters at TL23 to TL40, while at the lower TL's it was 1 to 2 V higher for the PM1R than for the EM4. At other times the PM1R discharge voltage was 1 to $3 \mathrm{~V}$ less than is shown in Figure 12, while for the EM4 the variation between runs was only $\pm 0.5 \mathrm{~V}$. The cause of the PM1R variability has not been confirmed. Trends in the doubles ratio versus TL were nearly the same for the two thrusters, except for TL01 to TL09 and TL13 to TL14 where $J^{++} / J^{+}$was higher for the PM1R than for the EM4, which was partly explained by the higher discharge voltage. Statistical error associated with probe signals on a given run was very small in the data of Figure 12, but the results at the lower TL's were subject to uncertainty due to variation in $V_{d}$ for the PM1R.
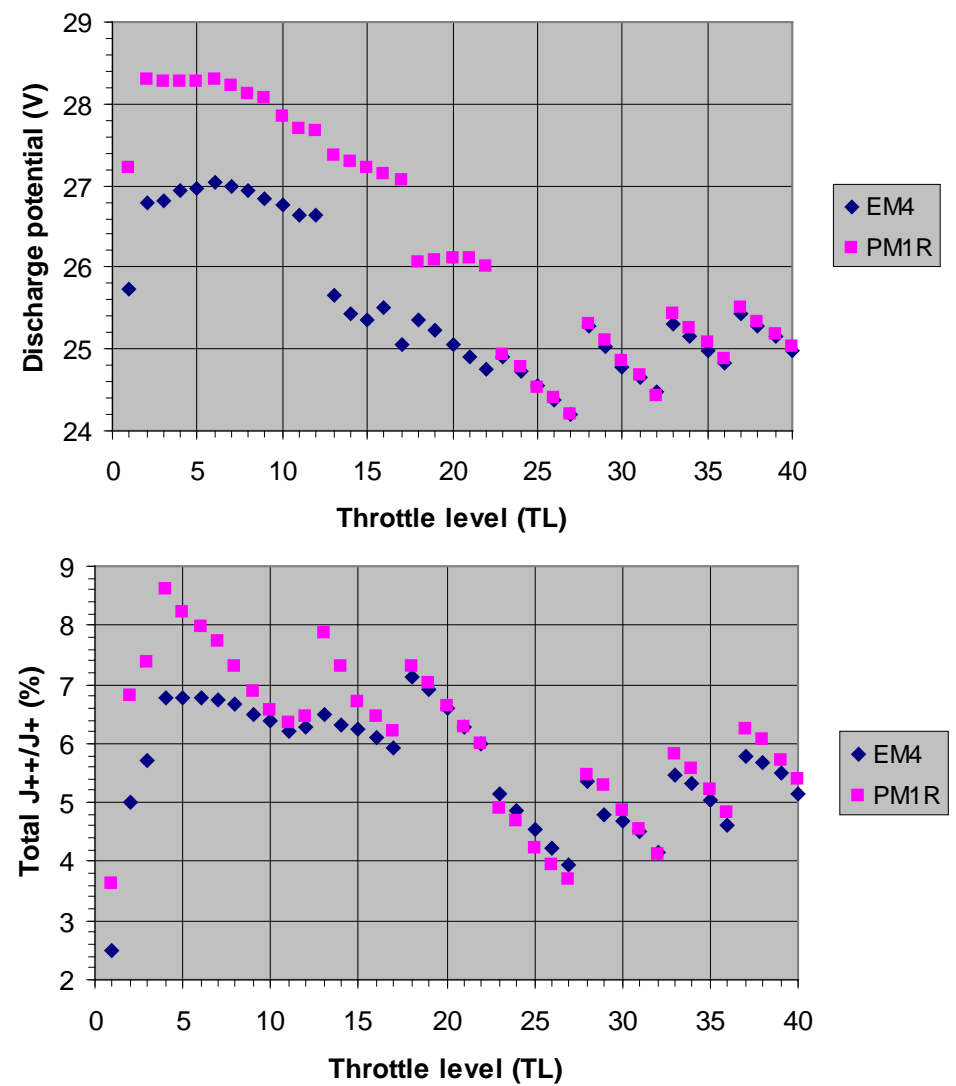

Figure 12.-Discharge voltage $V_{d}$ and total current ratio $\mathrm{J}^{++} / \mathrm{J}^{+}$ versus throttle level. 

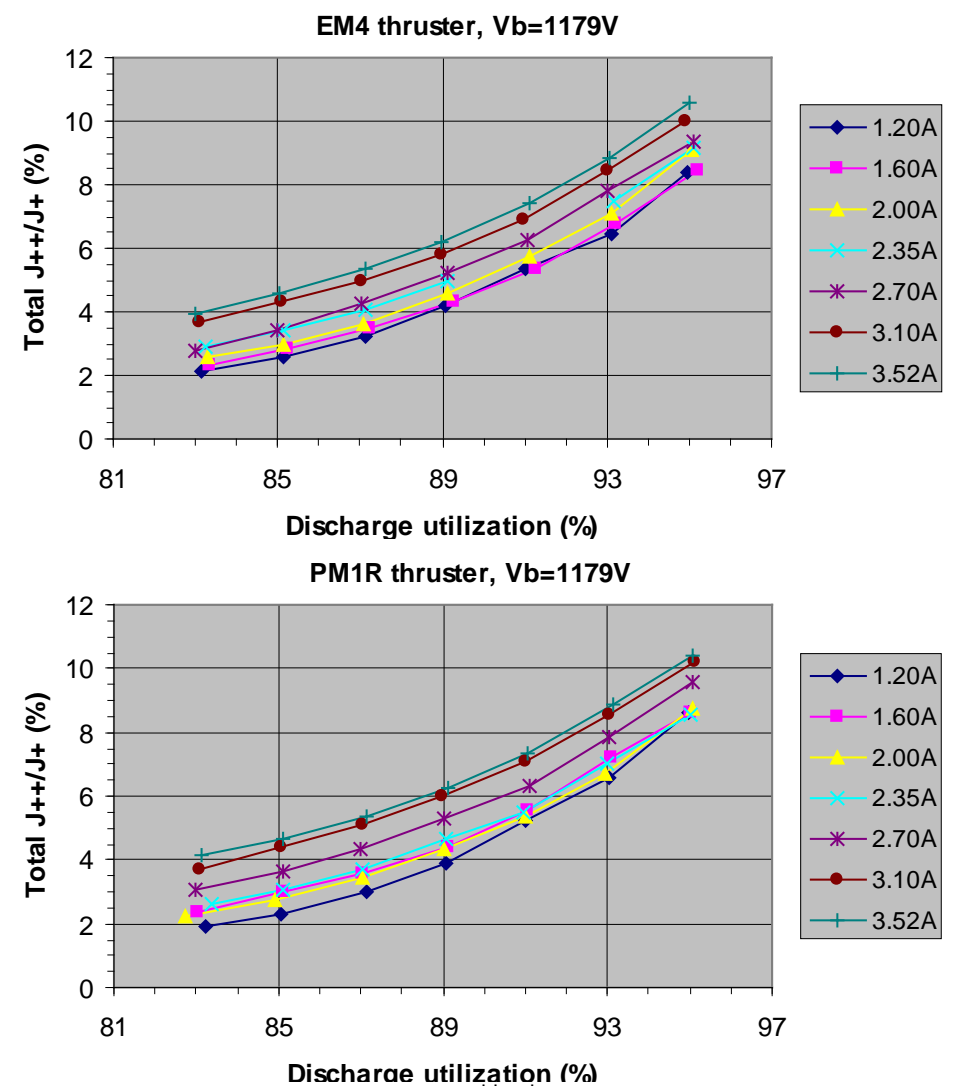

Figure 13.-Total current ratio $\mathrm{J}^{++} / \mathrm{J}^{+}$versus propellant utilization at $1179 \mathrm{~V}$ for a range of $J_{b}$.

Figures 13 and 14 show the total doubles ratio and the total triples ratio versus propellant utilization at $V_{b}=1179 \mathrm{~V}$ over a range of $J_{b}$, with separate graphs for the EM4 and PM1R thrusters. At the time of these measurements, $V_{d}$ for the PM1R was typically $0.5 \mathrm{~V}$ less than $V_{d}$ for the EM4, contrary to the pattern seen in Figure 12. Trending of $J^{++} / J^{+}$was very similar for the two thrusters (in the range of 2 to 10 percent for utilization from 83 to 95 percent). At a given utilization the doubles ratio increased by about 2 percent as $J_{b}$ increased from 1.2 to 3.5 A. The triples ratio at the higher TL's varied from 0.005 to 0.05 percent as utilization increased, with good agreement between EM4 and PM1R. For EM4 the triples ratio trending was about the same at all TL's, while for PM1R the ratio increased less rapidly with utilization at the lower TL's.

\subsection{Angular Dependence of $\boldsymbol{j}_{b}$ at Intermediate and Far-Field Distances}

Planar probe angular scans were recorded in the thruster mid-plane at $85 \mathrm{~cm}$ from the accel to enable a comparison with the $\mathrm{E} \times \mathrm{B}$ signals measured at $82 \mathrm{~cm}$. Measurements were extended to higher angles using RPA axial scans at 51-cm radial distance, as depicted on the graph in Figure 15. RPA scans were performed with grid-edge orientation, i.e. pointing toward the outermost apertures of the accel. This orientation maximized the signal over the range of the axial scan, demonstrating that the most divergent portion of the beam came from the outer apertures. As indicated in Figure 15, the exit plane was defined as the flat surface of the front mask, and the spherical accel surface extended to positive axial distances. Positive radial distances and positive angles were to the right of the neutralizer when facing the ion optics. Figure 16 shows $j_{b}$ at intermediate distances for the PM1R thruster, grouped into charts by beam voltage. 


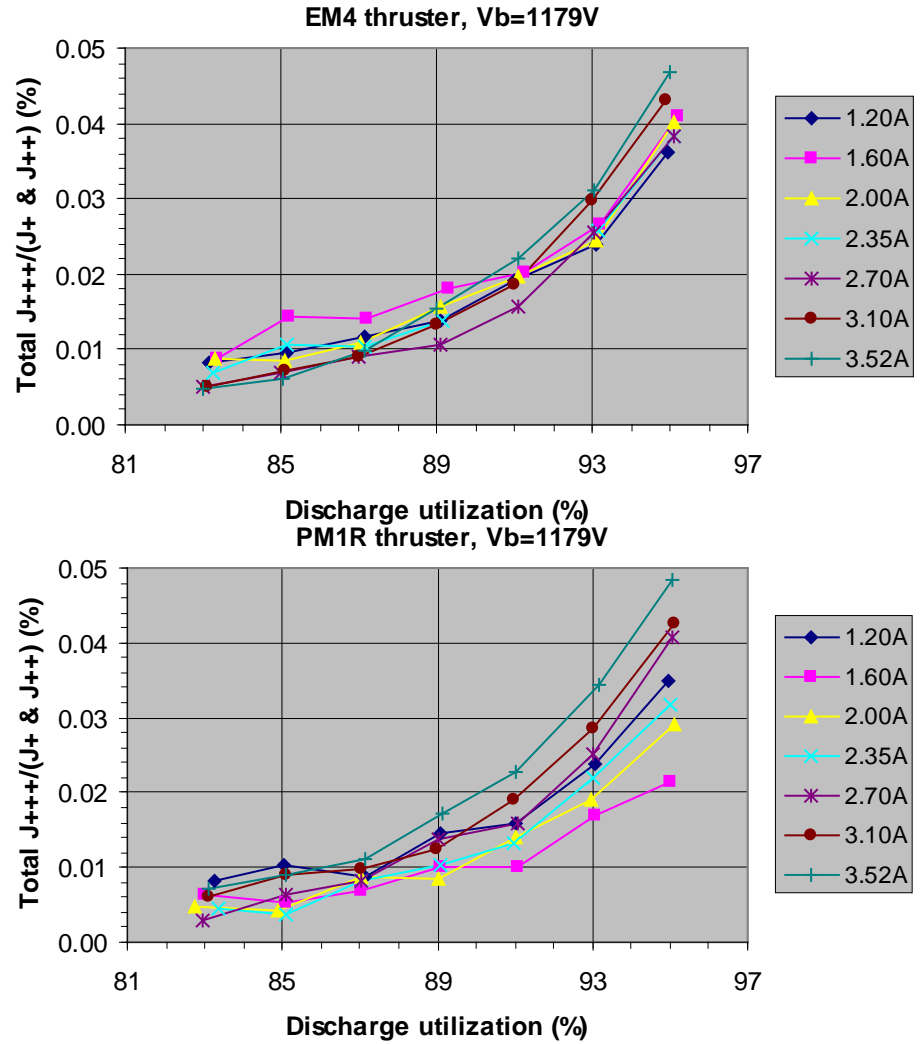

Figure 14.-Total current ratio $\mathrm{J}^{+++} /\left(\mathrm{J}^{+}+\mathrm{J}^{++}\right)$versus propellant utilization at $1179 \mathrm{~V}$ for a range of $J_{b}$.
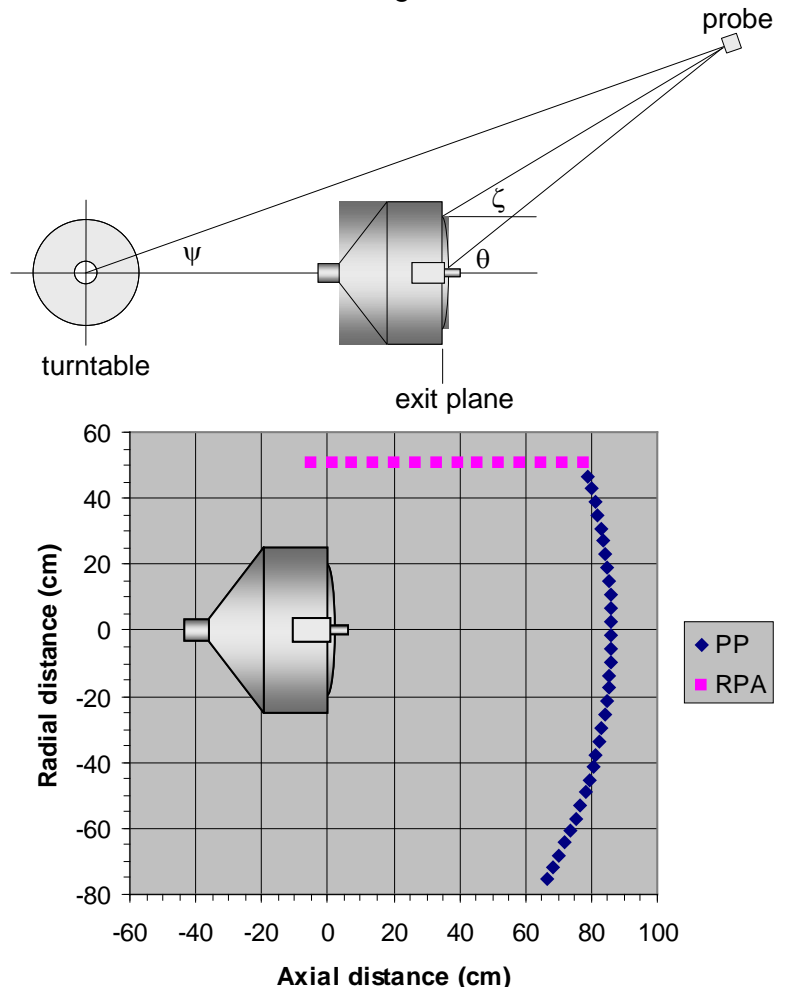

Figure 15.-Angle definitions and intermediate-distance probe locations in the thruster mid-plane. The planar probe used an angular scan in grid-normal orientation, and the RPA used an axial scan in grid-edge orientation. 
Here the angular and axial scans at each TL are plotted on the same graph as functions of the polar angle $\theta$, noting that the distance from the probe to the center of the exit plane was not held constant. Planar probe results are plotted from $\theta=-48^{\circ}$ to $+31^{\circ}$, and RPA results are from $\theta=+33^{\circ}$ to $+96^{\circ}$. At many of the throttle levels the peak of the $j_{b}$ distribution was offset from thruster centerline by about $-1^{\circ}$ in a slight departure from axisymmetry. The planar probe signal at $-20 \mathrm{~V}$ bias included components due to ions having less than the full beam energy and striking the probe at off-normal incidence. This flux arose mainly from charge-exchange collisions, as mentioned in Section 3.1. The RPA excluded the chargeexchange flux due to its repeller bias of $+40 \mathrm{~V}$. Hence the high-angle data points in Figure 16 show the fall-off of ions at the full beam energy, indicating that TL01, TL02, and TL03 produced fast ions with a higher divergence than was found at TL04 to TL40. The disparity was evident at angles greater than $+45^{\circ}$, and for TL01 and TL02 the flux of fast ions was nearly constant from $\theta=+70^{\circ}-+89^{\circ}$. Over most of the throttle table (TL04 to TL40) the current density of fast ions at $\theta=75^{\circ}-89^{\circ}$ was in the range of $10^{-6}$ to $10^{-4} \mathrm{~mA} / \mathrm{cm}^{2}$. Analysis of the RPA signal versus repeller bias showed that the charge-exchange flux ( $<2 \mathrm{eV}$ kinetic energy) was in the range of $3 \times 10^{-4}$ to $3 \times 10^{-3} \mathrm{~mA} / \mathrm{cm}^{2}$ depending on the total beam current $(1.00$ to $3.52 \mathrm{~A})$, and was nearly independent of beam voltage and axial position.

We measured the beam current density versus angle in the far-field (281 $\mathrm{cm}$ from the accel) with the planar probe at $-20 \mathrm{~V}$ collector bias and with the RPA at $+30 \mathrm{~V}$ repeller bias. The planar probe current density was 10 to 20 percent higher than the RPA current density, partly because the planar probe collected ions from the charge-exchange plasma and because the RPA had a smaller field-of-view (ca. $45^{\circ}$ half-angle). Variation in the doubles-to-singles ratio versus TL and versus distance may also have played a role, because the planar probe signal included the electron current ejected by ion impact, for which the yield was higher for $\mathrm{Xe}^{+2}$ than for $\mathrm{Xe}^{+1}$. For these reasons the RPA was preferred over the planar probe when measuring $j_{b}$ in the far-field. To derive the thrust correction factor for beam divergence one needs to know the angle of the $j_{b}$ vector at each measurement location. Using the $\mathrm{E} \times \mathrm{B}$ probe we showed that the signal at $82 \mathrm{~cm}$ from the accel was maximized in the grid-normal orientation (see Section 2.0). Therefore the angle of the $j_{b}$ vector in RPA scans at $281 \mathrm{~cm}$ was assumed to be the same as the turntable angle $\psi$ when in the range of $-15^{\circ}<\psi<+15^{\circ}$, corresponding to the perforated region of the accel grid. Outside of this range, we observed in RPA axial scans that the signal was maximized in gridedge orientation. Thus in the far-field scans the divergence angle $\delta$ was given by

$$
\delta=\psi \text { if }-15^{\circ}<\psi<+15^{\circ} \text {, otherwise } \delta=\zeta,
$$

where $\zeta$ was the probe angle having its vertex at the grid edge (see Fig. 15). The rationale used here for determining $\delta$ helped to reduce the error due to the measuring $j_{b}$ at a finite distance from the $36-\mathrm{cm}$ diameter source region. Figure 17 shows $j_{b}$ versus angle at 40 throttle levels for the PM1R, from which we derived thrust correction factors for beam divergence (see Section 3.7). 
PM1R thruster, $\mathrm{Vb}=\mathbf{2 7 5}-\mathbf{9 3 6} \mathrm{V}$
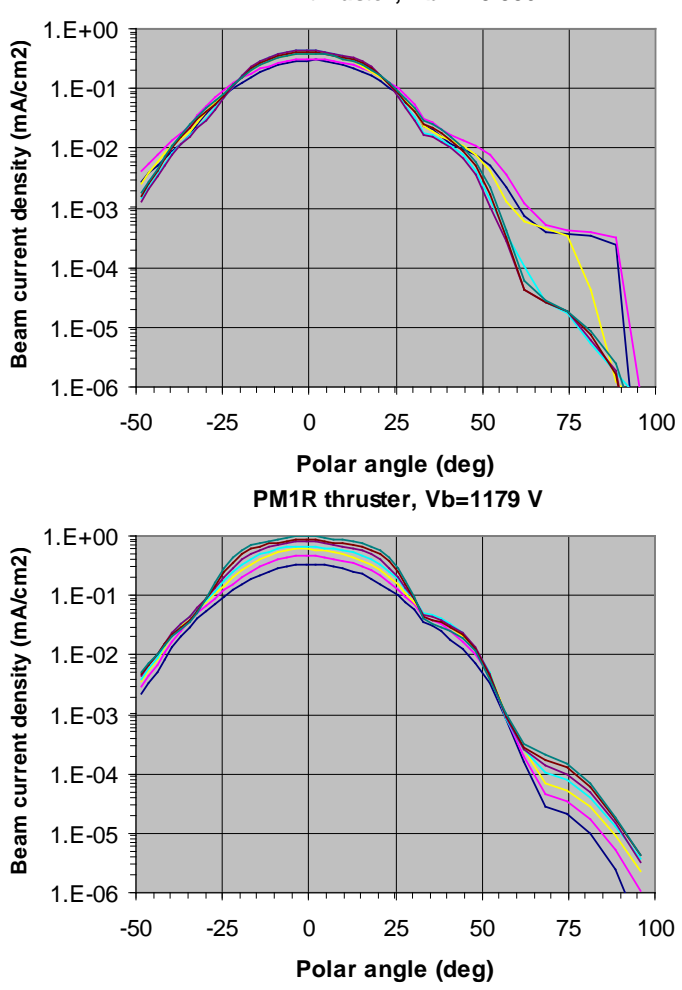

PM1R thruster, Vb=1567 V

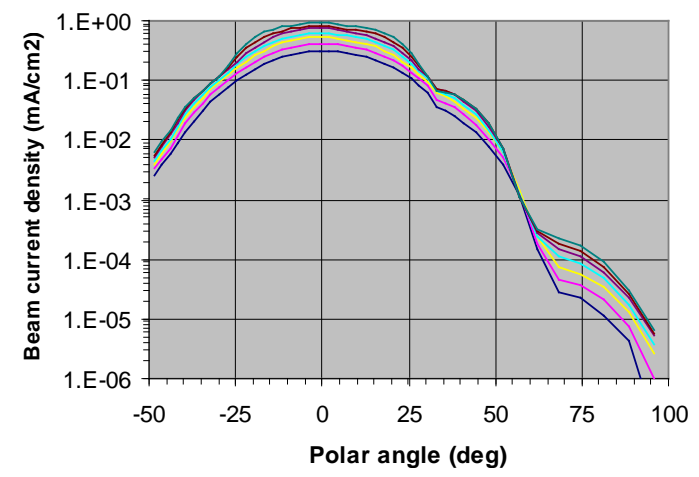

PM1R thruster, Vb=1021 V

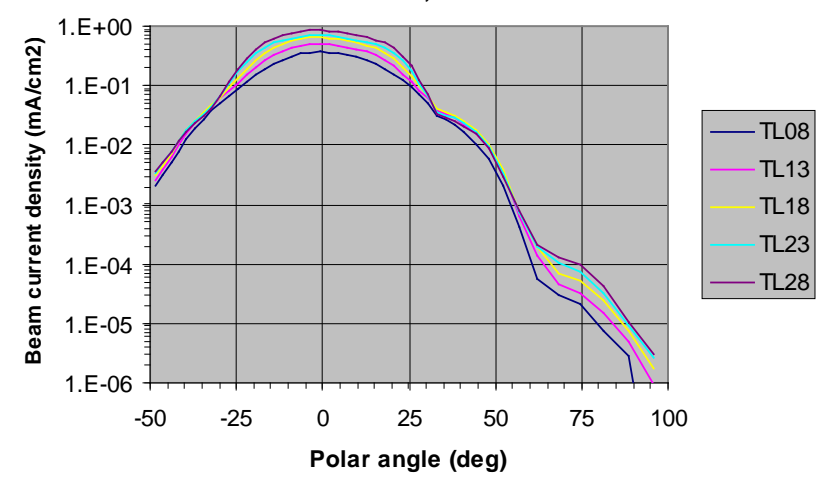

PM1R thruster, Vb=1396 V
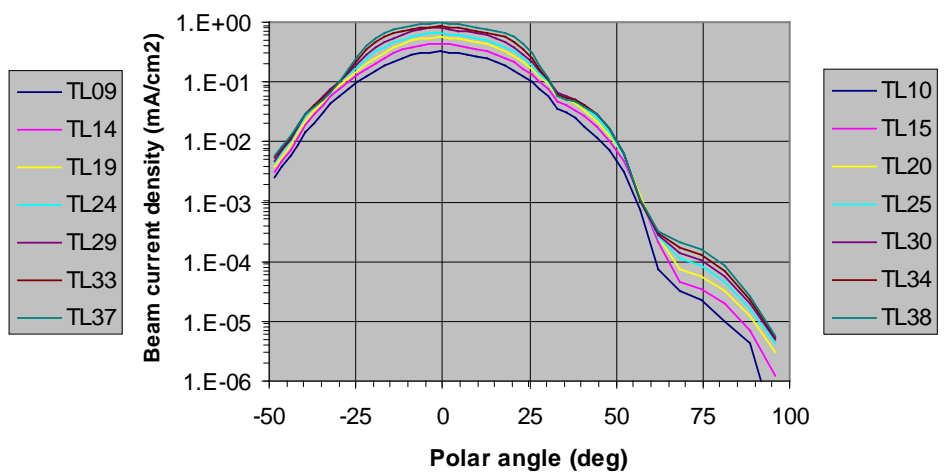

PM1R thruster, Vb=1800 V
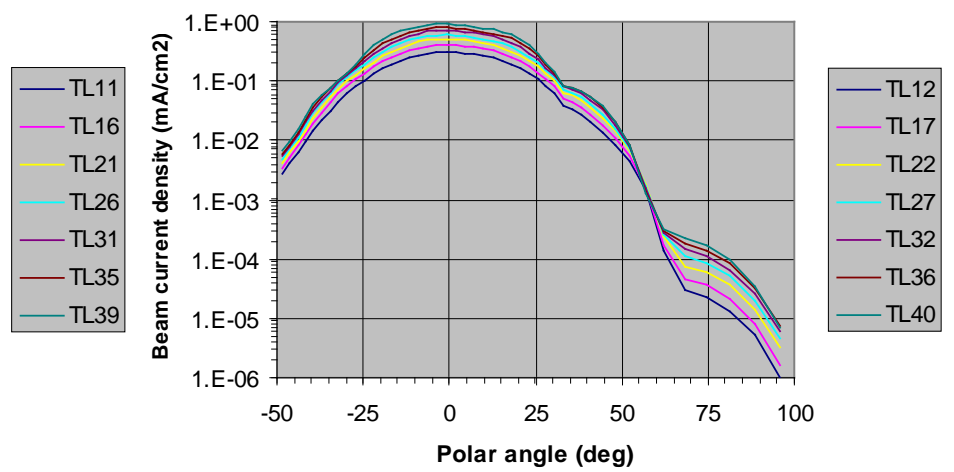

Figure 16.-Beam current density $j_{b}$ versus polar angle $\theta$ for the PM1R at the locations in Figure 15 . The curves show planar probe data from $-48^{\circ}$ to $+31^{\circ}$ and RPA data from $+33^{\circ}$ to $+96^{\circ}$. 
PM1R thruster, $281 \mathrm{~cm}$ from accel, Vb=275-936 V
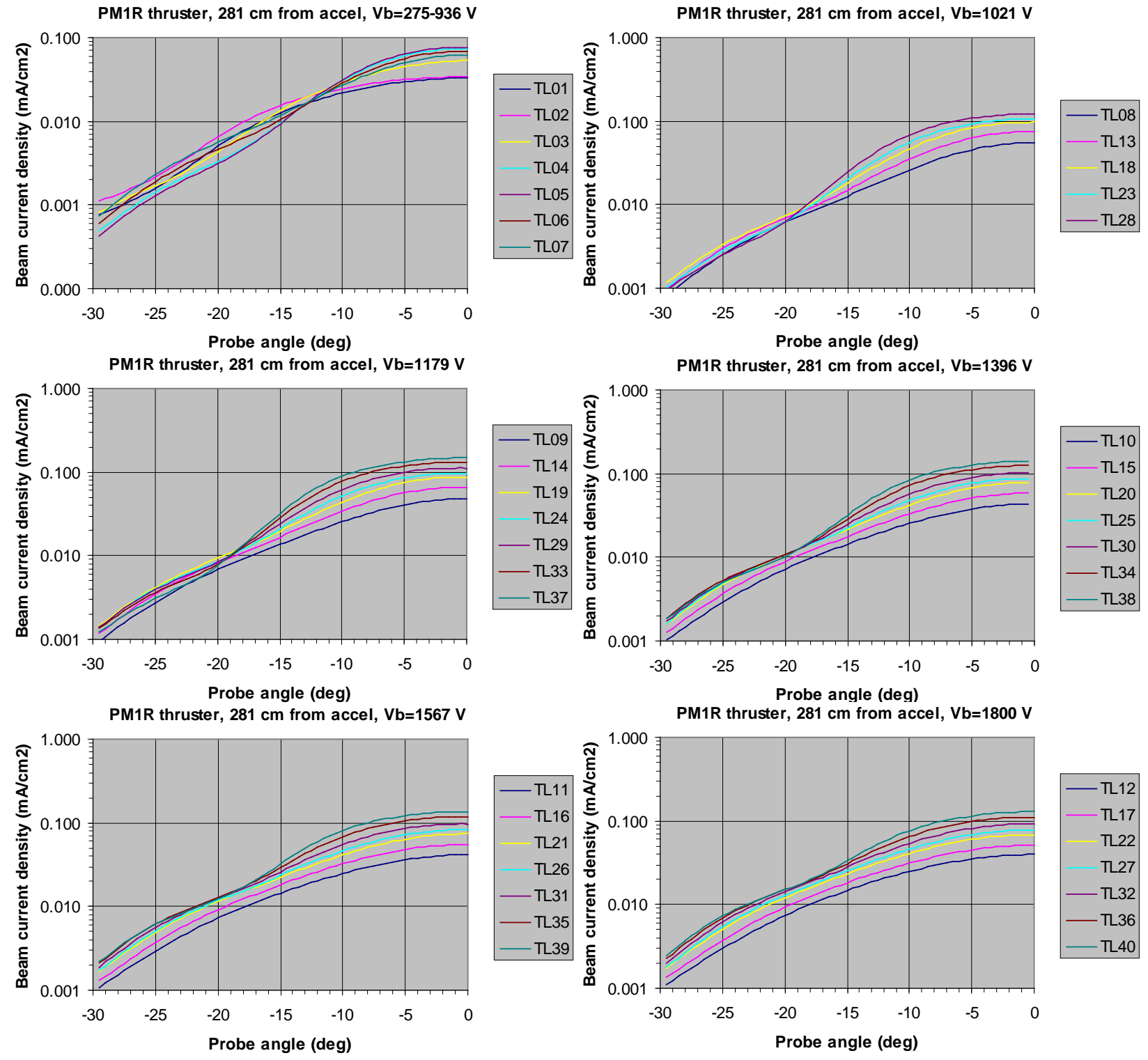

Figure 17.-Beam current density $j_{b}$ versus probe angle $\psi$ at $281 \mathrm{~cm}$ from the accel grid for the PM1R. 


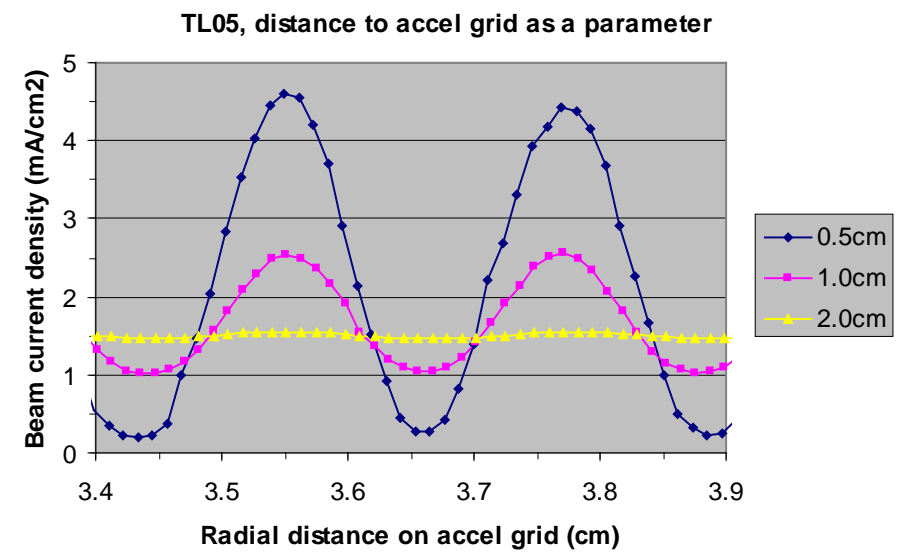

Figure 18.-Beam current density $j_{b}$ versus radial distance at $0.5,1.0$, and $2.0 \mathrm{~cm}$ from the accel grid. The $0.5 \mathrm{~cm}$ points are for the EM4. The 1.0 and $2.0 \mathrm{~cm}$ points are for the PM1R.

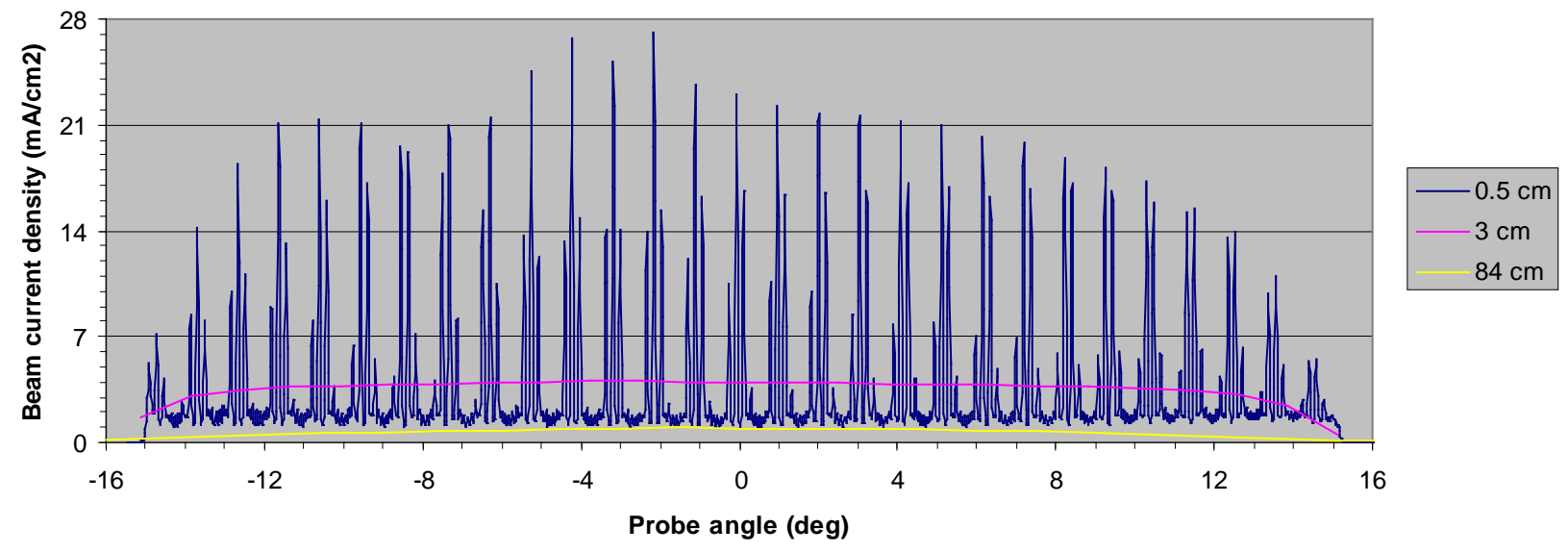

Figure 19.-Beam current density $j_{b}$ versus probe angle $\psi$ for the EM4 thruster at TL40.

\subsection{Radial and Axial Dependence of $j_{b}$ at $0.5-2.0 \mathrm{~cm}$}

To provide data for comparison with theoretical modeling of beamlet profiles we measured the current density at 0.5 to $2.0 \mathrm{~cm}$ from the accel grid in the thruster mid-plane. Figure 18 includes scans for the EM4 and PM1R thrusters. It shows radial profiles of $j_{b}$ for two individual beamlets with distance from the accel to the probe as a parameter, demonstrating that for TL05 the merger of beamlets was nearly complete at $2.0 \mathrm{~cm}$ from the accel. Figure 19 shows a sweep across the full width of the accel for the EM4, along with the smooth profiles of current density measured at 3 and $84 \mathrm{~cm}$. Peaks from more than 200 individual beamlets were detected at $0.5 \mathrm{~cm}$, with intensities that followed the periodic variation in vertical offset between the aperture centers and the probe path. This periodicity occurred because of a design feature of the EM4 thruster that had the rows of apertures clocked by $10^{\circ}$ relative to the mid-plane.

Figure 20 shows probe scans over a 2 -cm wide region at $0.5 \mathrm{~cm}$ from the EM4 accel to illustrate the variation in beamlet divergence versus throttle level. To clarify this comparison, the ordinate of the graphs equals $j_{b}$ divided by its average value, namely $j_{b}\left(\mathrm{~mA} / \mathrm{cm}^{2}\right) / J_{b}(\mathrm{~mA}) / 1071 \mathrm{~cm}^{2}$. The trends were as follows:

- Among five operating points having $J_{b}=1.20$ A (TL02, 05, 08, 10, 12), the minimum beamlet divergence was at $V_{b}=679 \mathrm{~V}$ (TL05), which corresponded to optimal focusing. At $679 \mathrm{~V}$ the beamlets appeared in high definition, while at $300 \mathrm{~V}$ (TL02) they were almost fully merged. With 
increasing beam voltage, namely 1021 to $1800 \mathrm{~V}$ (TL08, 10, and 12), there was an increase in divergence as the plasma sheath expanded upstream of the screen grid and the beamlets became over-focused. TL12 was known to produce over-focusing, especially on the outer apertures of the ion optics (Ref. 11).

- At 2.35 A (TL23, 25, 27) and at 3.52 A (TL38 and 40) an increase in $V_{b}$ at fixed $J_{b}$ led to filling in of the $j_{b}$ profile in the region between apertures but had less of an effect on $j_{b}$ at the beamlet center. $1179 \mathrm{~V}$ (TL37) was known to produce a higher rate of accel aperture wall erosion than $1800 \mathrm{~V}$ (TL40) (Refs. 5 and 11). This was, in part, due to under-focusing, which increased the beamlet cross-section in the inter-grid region, leading to more charge-exchange ions created in regions where they could have a trajectory to the accel wall.

- At $1396 \mathrm{~V}$ (TL10, 25, and 38) and $1800 \mathrm{~V}$ (TL12, 27, and 40), an increase in $J_{b}$ at fixed $V_{b}$ produced a reduction in beamlet divergence as the sheath contracted upstream of the screen grid.
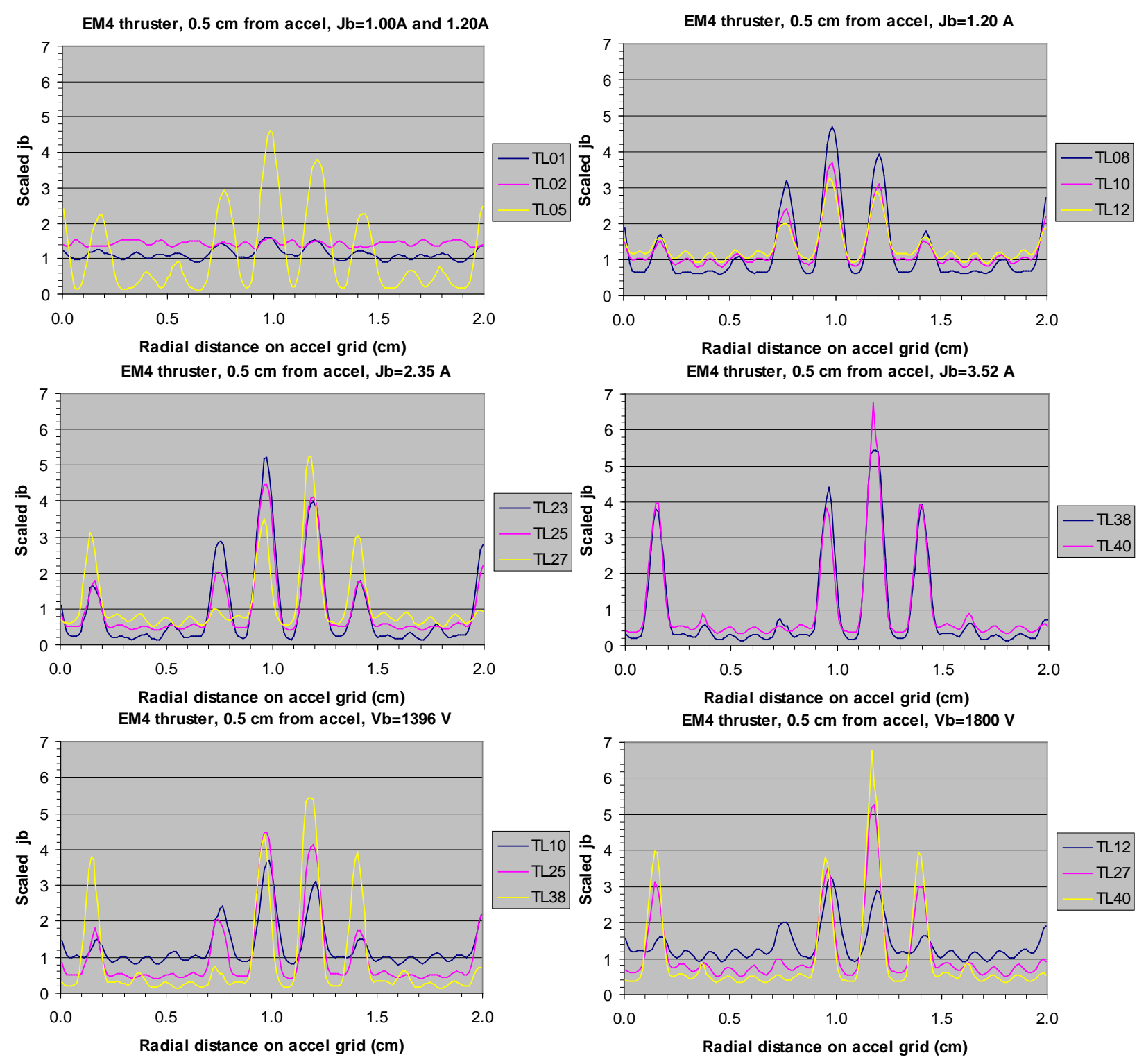

Figure 20.-Scaled beam current density $j_{b}$ versus radial distance at $0.5 \mathrm{~cm}$ from the accel grid for the EM4. 


\subsection{Thrust Loss Correction Factors}

The overall thruster efficiency $\eta_{t}$ is proportional to the squares of the correction factors associated with doubly-charged ions $(\alpha)$ and with beam divergence $(\beta)$ :

$$
\begin{gathered}
\eta_{t}=\gamma^{2} \eta_{u} \eta_{e}=\alpha^{2} \beta^{2} \eta_{u} \frac{J_{b}\left(V_{b}+V_{g}\right)}{P_{\text {in }}}=\frac{F g_{0} I_{s p}}{2 P_{\text {in }}}, \\
\alpha=\frac{1+\frac{\sqrt{2}}{2} J^{++} / J^{+}}{1+J^{++} / J^{+}}, \\
\beta=\int_{0}^{-45^{\circ}} j_{b} \cos \delta \sin \psi d \psi / \int_{0}^{-45^{\circ}} j_{b} \sin \psi d \psi
\end{gathered}
$$

Here $\beta$ is the ratio of the axial component of beam current to the total beam current $J_{b}$. Equation (4) assumes axisymmetric flow at an average speed that is independent of angle, which is usually a good approximation for a gridded ion thruster. The integrand in the numerator is the product of the axial component of beam current density $j_{b} \cos \delta$ and the area weighting factor $\sin \psi \mathrm{d} \psi$. The scan range was from $\psi=0^{\circ}$ to $-29.5^{\circ}$ in $0.5^{\circ}$ steps, i.e., $\delta=0^{\circ}$ to $-33.0^{\circ}$. For integrating Equation (4), the data were extrapolated to reduce the truncation error by assuming an exponential fall-off in $j_{b}$ versus $\psi$ for angles between $-29.5^{\circ}$ and $-45^{\circ}$. Our results are based on sampling a small portion of the far-field plume and may be affected by departures from axisymmetry that were not measured.

Figure 21 shows the correction factors versus throttle level for the PM1R, with error bars for the estimated systematic uncertainty. Random error in these measurements is small by comparison. Thrust loss due to divergence (ca. 2 to 4 percent) was greater than the loss due to doubly-charged ions (ca. 1 to 2 percent). The factors $\alpha$ and $\beta$ trended in opposite directions versus beam voltage and current, which moderated the dependency for the combined factor $\gamma$. At throttle levels with higher utilization (93 percent, TL02 to TL22) the combined factor stayed mostly in the range of 0.94 to 0.95 , while at lower utilization (89 percent, TL23 to TL40) it was in the range on 0.95 to 0.96 . Of the operating points in the standard throttle table, TL02 had the greatest thrust loss from divergence and TL05 had the smallest. At TL01 to TL03 the divergence loss could be more than what is shown in Figure 21, because of the fast ion flux at angles beyond the range of the far-field probe scans (see Fig. 16). Trending at a given utilization over most of the throttle table (TL05 to TL40) was as follows:

- The doubles correction factor $\alpha$ improved with increasing $V_{b}$ at fixed $J_{b}$ and utilization, because the discharge voltage decreased slightly as $V_{b}$ increased, thereby suppressing $\mathrm{Xe}^{+2}$ production.

- The divergence correction factor $\beta$ degraded with increasing $V_{b}$ due to the increase in sheath curvature.

- $\quad$ The divergence correction factor $\beta$ improved with increasing $J_{b}$ due to the reduction in sheath curvature.

Trends in $\beta$ versus TL in Figure 21 are not apparent in the profiles of $j_{b}$ versus radial distance at $3 \mathrm{~cm}$ from the accel (see Fig. 11). The latter were measured downstream of where the beamlets merged using a probe that collected current from multiple apertures on the accel grid, which allowed an assessment of beam flatness and axisymmetry but was not indicative of how $\beta$ would vary as a function of $V_{b}$ and $J_{b}$. Hence, the far-field divergence was a set mainly by beamlet focusing rather than by the distribution of beamlet current versus radial position. 


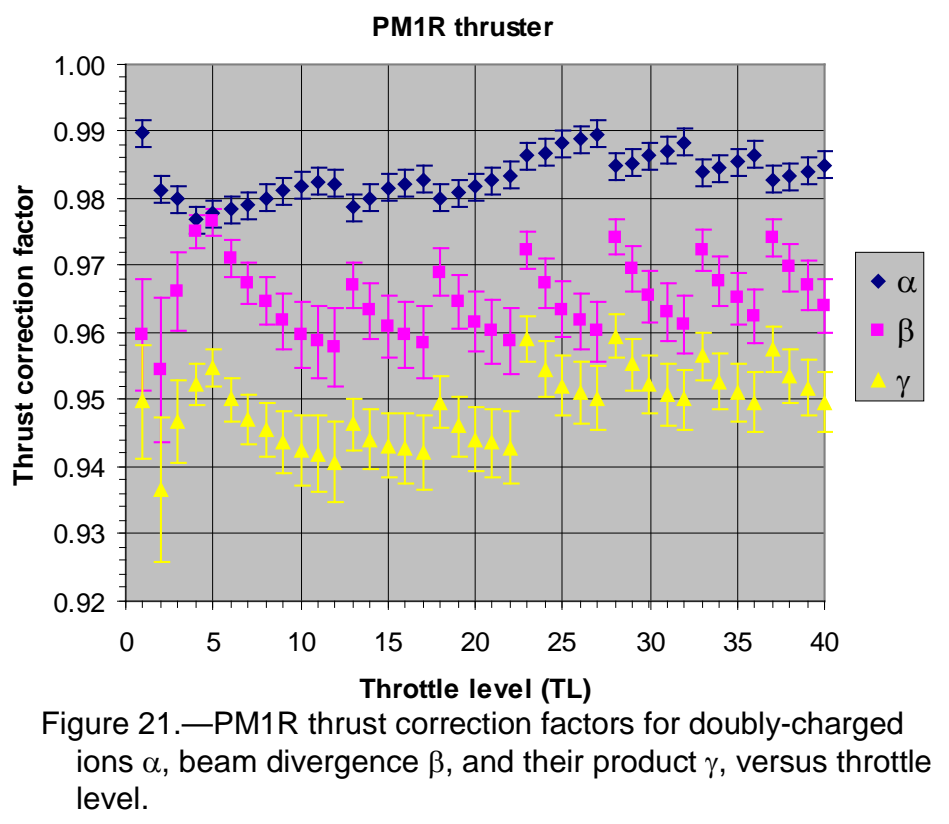

\subsection{Conclusion}

We have investigated the properties of the NEXT ion beam to better understand thruster performance, life-limiting factors, and plume interactions with the spacecraft. Measurements were performed with the EM4 and PM1R thrusters at 40 operating points that comprise the standard throttle table. They included the current densities of $\mathrm{Xe}^{+1}, \mathrm{Xe}^{+2}$, and $\mathrm{Xe}^{+3}$ as functions of radial position near the accel grid, and the beam current density $j_{b}$ as a function of angle and axial distance. Probe scans were confined to the thruster mid-plane. Departures from axisymmetry were evident in data recorded near the accel. An important feature of the setup was to scan the probes at a constant distance from the spherical grid surface with a viewing direction normal to the surface, which simplified the data reduction.

Plume centerline was generally a local minimum in the doubles-to-singles ratio $j^{++} / j^{+}$, with maxima occurring at radial distances of 5 to $8 \mathrm{~cm}$ on either side of it. Presumably this would appear as an annular maximum in $j^{++} / j^{+}$if the entire accel grid were measured. The total current ratio $\mathrm{J}^{++} / \mathrm{J}^{+}$was derived under the assumption that mid-plane data were representative of the entire beam, using $j^{++} / j^{+}$measured by a collimated $\mathrm{E} \times \mathrm{B}$ probe at $82 \mathrm{~cm}$ and $j_{b}$ measured at $3 \mathrm{~cm}$ from the accel grid. Axial scans of the $\mathrm{E} \times \mathrm{B}$ probe on centerline provided a correction for the depletion of $\mathrm{Xe}^{+1}$ relative to $\mathrm{Xe}^{+2}$ by charge-exchange collisions. Production of $\mathrm{Xe}^{+2}$ and $\mathrm{Xe}^{+3}$ was examined as a function of propellant utilization efficiency over the range of beam current $J_{b}=1.2$ to $3.5 \mathrm{~A}$ at $V_{b}=1179 \mathrm{~V}$ to assess performance and lifetime implications for an extended throttle table.

The angular dependence of $j_{b}$ was measured at an intermediate distance range (50 to $85 \mathrm{~cm}$ from the accel) to provide data for plume modeling, and it was measured in the far-field ( $285 \mathrm{~cm}$ from the accel) to evaluate the thrust loss due to beam divergence. The flux of energetic ions at $89^{\circ}$ from centerline was 100 times higher at the two lowest throttle levels (TL01 and 02) than at the other TL's. Beamlet profiles were measured at 0.5 to $2.0 \mathrm{~cm}$ from the accel for comparison with modeling, showing that the merger of beamlets was nearly complete at $2.0 \mathrm{~cm}$. Beamlet focusing rather than beam flatness was the main factor in determining far-field plume divergence. Thrust loss correction factors were derived for doubly-charged ions and for plume divergence. At throttle levels with higher utilization ( $\eta_{u d}=93$ percent) the combined correction factor stayed mostly in the range of 0.94 to 0.95 , while at lower utilization (89 percent) it was in the range on 0.95 to 0.96 . 



\section{Appendix A.-Total Current Ratios}

As noted in Section 2.0, the charge-state distribution measured with a collimated probe in the far-field is the same as what would be measured at the accel grid, assuming there is a correction for chargeexchange collisions with background gas (Section 3.1). In calculating the total current for each charge state one must apply a weighting factor proportional to the beam current density at the accel, which we measured using the miniature planar probe (Section 3.3). Neglecting the small contribution from triplycharged xenon, the beam current density is

$$
j_{b}=j^{+}+j^{++}=\frac{1}{1+\rho} j_{b}+\frac{\rho}{1+\rho} j_{b}, \quad \rho \equiv \frac{j^{++}}{j^{+}}
$$

For an assumed axisymmetric beam profile the ratio of total $\mathrm{Xe}^{+2}$ current to total $\mathrm{Xe}^{+1}$ current is

$$
J^{++} / J^{+}=\frac{\int_{-15^{\circ}}^{+15^{\circ}} \frac{\rho}{1+\rho} j_{b} \sin \psi d \psi}{\int_{-15^{\circ}}^{+15^{\circ}} \frac{1}{1+\rho} j_{b} \sin \psi d \psi} \approx \frac{\sum_{n=1}^{25} \frac{\rho_{n}}{1+\rho_{n}} j_{b n} \psi_{n}}{\sum_{n=1}^{25} \frac{1}{1+\rho_{n}} j_{b n} \psi_{n}}
$$

where $\psi$ is the probe angle shown in Figure 15. A further assumption in Equation (A2) is that the direction of the measured $j_{b}$ is normal to the area element in the surface integrals. We measured $\rho_{n}$ and $j_{b n}$ at 25 angles $\psi_{n}$ in the mid-plane of the thruster (Figs. 10 and 11). The integration was across the full grid diameter to average the current densities recorded on either side of centerline. In some cases we recorded the current density of triply-charged xenon $j^{+++}$from which the total current ratio $J^{+++} /\left(J^{+}+J^{++}\right)$was derived as follows:

$$
\begin{gathered}
j_{b}=j^{+}+j^{++}+j^{+++}=\frac{1}{1+\sigma} j_{b}+\frac{\sigma}{1+\sigma} j_{b}, \quad \sigma \equiv \frac{j^{+++}}{j^{+}+j^{++}}, \\
\frac{J^{+++}}{J^{+}+J^{++}}=\frac{\int_{-15^{\circ}}^{+15^{\circ}} \frac{\sigma}{1+\sigma} j_{b} \sin \psi d \psi}{\int_{-15^{\circ}}^{+15^{\circ}} \frac{1}{1+\sigma} j_{b} \sin \psi d \psi} \approx \frac{\sum_{n=1}^{25} \frac{\sigma_{n}}{1+\sigma_{n}} j_{b n} \psi_{n}}{\sum_{n=1}^{25} \frac{1}{1+\sigma_{n}} j_{b n} \psi_{n}}
\end{gathered}
$$




\section{References}

1. M.J. Patterson and S.W. Benson, "NEXT Ion Propulsion System Development Status and Performance,” AIAA-2007-5199, 43rd Joint Propulsion Conference, 8-11 July 2007, Cincinnati, $\mathrm{OH}$.

2. D.A. Herman, G.C. Soulas, and M.J. Patterson, "Performance Evaluation of the Prototype-Model NEXT Ion Thruster,” AIAA-2007-5212, 43rd Joint Propulsion Conference, 8-11 July 2007, Cincinnati, $\mathrm{OH}$.

3. G.C. Soulas and M.J. Patterson, "NEXT Ion Thruster Performance Dispersion Analyses,” AIAA2007-5213, 43rd Joint Propulsion Conference, 8-11 July 2007, Cincinnati, OH.

4. D.A. Herman, G.C. Soulas, and M.J. Patterson, "Performance Characteristics of the NEXT LongDuration Test after 16,550 h and $337 \mathrm{~kg}$ of Xenon Processed,” AIAA-2008-4527, 44th Joint Propulsion Conference, 21-23 July 2008, Hartford, CT.

5. D.A. Herman, G.C. Soulas, and M.J. Patterson, "NEXT Long-Duration Test Plume and Wear Characteristics after 16,550 h of Operation and 337 kg of Xenon Processed," AIAA-2008-4919, 44th Joint Propulsion Conference, 21-23 July 2008, Hartford, CT.

6. G.C. Soulas, M.J. Patterson, L. Pinero, D.A. Herman, and J.S. Snyder, "NEXT Single String Integration Test Results,” AIAA-2009-4816, 45th Joint Propulsion Conference, 2-5 Aug 2009, Denver, CO.

7. M.W. Crofton, et al., "Characterization of the NASA NEXT Thruster," AIAA-2009-4815, 45th Joint Propulsion Conference, 2-5 Aug 2009, Denver, CO.

8. M.J. Patterson, “NEXT Study of Thruster Extended Performance (NEXT STEP),” Paper AIAA 20064664, 42nd Joint Propulsion Conference, 9-12 July 2006, Sacramento, CA.

9. M.J. Patterson, "NEXT Study of Thruster Extended Performance II (NEXT STEP II)," AIAA-20084808, 44th Joint Propulsion Conference, 21-23 July 2008, Hartford, CT.

10. J.L. Van Noord, "Lifetime Assessment of the NEXT Ion Engine,” AIAA-2007-5274, 43rd Joint Propulsion Conference, 8-11 July 2007, Cincinnati, OH.

11. J.L. Van Noord and D.A. Herman, "Application of the NEXT Ion Thruster Lifetime Assessment to Thruster Throttling,” AIAA-2008-4526, 44th Joint Propulsion Conference, 21-23 July 2008, Hartford, CT.

12. K.D. Diamant, J.E. Pollard, M.W. Crofton, and M.J. Patterson, "Thrust Stand Characterization of the NASA NEXT Thruster,” AIAA-2010-6701, 46th Joint Propulsion Conference, 25-28 July 2010, Nashville, TN.

13. A. Snyder, H. Kamhawi, M. Patterson, and M. Britton, "Single-String Integration Test Measurements of the NEXT Ion Engine Plume,” AIAA-2004-3790, 40th Joint Propulsion Conference, 11-14 July 2004, Ft. Lauderdale, FL.

14. T.A. Hickman, L.A. Arrington, M.M. Frandina, and G.C. Soulas, "Overview of Diagnostics for the NEXT Long Duration Test,” Paper AIAA-2005-4064, 41st Joint Propulsion Conference, 10-13 July 2005, Tucson, AZ.

15. J.S. Sovey, “Improved ion containment using a ring-cusp ion thruster,” J. Spacecraft and Rockets, Vol. 21, No. 5, 1984, pp. 488-495.

16. V.K. Rawlin, J.S. Sovey, J.R. Anderson, and J.E. Polk, "NSTAR Flight Thruster Qualification Testing,” AIAA-98-3936, 34th Joint Propulsion Conference, 13-15 July 1998, Cleveland, OH.

17. A. Galejs and C.E. Kuyatt, "Focusing and Dispersing Properties of a Stigmatic Crossed-Field Energy Analyzer,” J. Vac. Sci. Technol., Vol. 15, No. 3, 1978, pp. 865-867.

18. J.E. Pollard and K.D. Diamant, "Hall Thruster Plume Shield Wake Structure," AIAA-2003-5018, 39th Joint Propulsion Conference, 20-23 July 2003, Huntsville, AL.

19. J.S. Miller, S.H. Pullins, D.J. Levandier, Y. Chiu, and R.A. Dressler, "Xenon Charge Exchange Cross Sections for Electrostatic Thruster Models,” J. Applied Physics, Vol. 91, No. 3, 2002, pp. 984-991. 


\begin{tabular}{|c|c|c|}
\hline \multicolumn{2}{|c|}{ REPORT DOCUMENTATION PAGE } & $\begin{array}{l}\text { Form Approved } \\
\text { OMB No. 0704-0188 }\end{array}$ \\
\hline \multicolumn{3}{|c|}{$\begin{array}{l}\text { The public reporting burden for this collection of information is estimated to average } 1 \text { hour per response, including the time for reviewing instructions, searching existing data sources, gathering and maintaining the } \\
\text { data needed, and completing and reviewing the collection of information. Send comments regarding this burden estimate or any other aspect of this collection of information, including suggestions for reducing this } \\
\text { burden, to Department of Defense, Washington Headquarters Services, Directorate for Information Operations and Reports (0704-0188), 1215 Jefferson Davis Highway, Suite } 1204 \text {, Arlington, VA } 22202-4302 \text {. } \\
\text { Respondents should be aware that notwithstanding any other provision of law, no person shall be subject to any penalty for failing to comply with a collection of information if it does not display a currently valid OMB } \\
\text { control number. } \\
\text { PLEASE DO NOT RETURN YOUR FORM TO THE ABOVE ADDRESS. }\end{array}$} \\
\hline $\begin{array}{l}\text { 1. REPORT DATE (DD-MM-YYYY) } \\
01-09-2010\end{array}$ & $\begin{array}{l}\text { 2. REPORT TYPE } \\
\text { Technical Memorandum }\end{array}$ & 3. DATES COVERED (From - To) \\
\hline \multirow{3}{*}{\multicolumn{2}{|c|}{$\begin{array}{l}\text { 4. TITLE AND SUBTITLE } \\
\text { Spatially-Resolved Beam Current and Charge-State Distributions for the NEXT Ion Engine }\end{array}$}} & 5a. CONTRACT NUMBER \\
\hline & & 5b. GRANT NUMBER \\
\hline & & 5c. PROGRAM ELEMENT NUMBER \\
\hline \multirow{3}{*}{\multicolumn{2}{|c|}{$\begin{array}{l}\text { 6. AUTHOR(S) } \\
\text { Pollard, James, E.; Diamant, Kevin, D.; Crofton, Mark, W.; Patterson, Michael, J.; Soulas, } \\
\text { George, C. }\end{array}$}} & 5d. PROJECT NUMBER \\
\hline & & 5e. TASK NUMBER \\
\hline & & $\begin{array}{l}\text { 5f. WORK UNIT NUMBER } \\
\text { WBS 346620.04.08.02.02.01 }\end{array}$ \\
\hline \multicolumn{2}{|c|}{$\begin{array}{l}\text { 7. PERFORMING ORGANIZATION NAME(S) AND ADDRESS(ES) } \\
\text { National Aeronautics and Space Administration } \\
\text { John H. Glenn Research Center at Lewis Field } \\
\text { Cleveland, Ohio 44135-3191 }\end{array}$} & $\begin{array}{l}\text { 8. PERFORMING ORGANIZATION } \\
\text { REPORT NUMBER } \\
\text { E-17413 }\end{array}$ \\
\hline \multirow{2}{*}{\multicolumn{2}{|c|}{$\begin{array}{l}\text { 9. SPONSORING/MONITORING AGENCY NAME(S) AND ADDRESS(ES) } \\
\text { National Aeronautics and Space Administration } \\
\text { Washington, DC 20546-0001 }\end{array}$}} & $\begin{array}{l}\text { 10. SPONSORING/MONITOR'S } \\
\text { ACRONYM(S) } \\
\text { NASA }\end{array}$ \\
\hline & & $\begin{array}{l}\text { 11. SPONSORING/MONITORING } \\
\text { REPORT NUMBER } \\
\text { NASA/TM-2010-216790 }\end{array}$ \\
\hline \multicolumn{3}{|c|}{$\begin{array}{l}\text { 12. DISTRIBUTIONIAVAILABILITY STATEMENT } \\
\text { Unclassified-Unlimited } \\
\text { Subject Category: } 20 \\
\text { Available electronically at http://gltrs.grc.nasa.gov } \\
\text { This publication is available from the NASA Center for AeroSpace Information, 443-757-5802 }\end{array}$} \\
\hline
\end{tabular}

\section{SUPPLEMENTARY NOTES}

\section{ABSTRACT}

Plume characterization tests with the 36-cm NEXT ion engine are being performed at The Aerospace Corporation using engineering-model and prototype-model thrusters. We have examined the beam current density and xenon charge-state distribution as functions of position on the accel grid. To measure the current density ratio $j^{++} / j^{+}$, a collimated Eprobe was rotated through the plume with the probe oriented normal to the accel electrode surface at a distance of $82 \mathrm{~cm}$. The beam current density $j_{b}$ versus radial position was measured with a miniature planar probe at $3 \mathrm{~cm}$ from the accel. Combining the $j^{++} / j^{+}$and $j_{b}$ data yielded the ratio of total Xe $\mathrm{Xe}^{+2}$ current to total Xe $\mathrm{e}^{+1}$ current $\left(J^{++} / J^{+}\right)$at forty operating points in the standard throttle table. The production of $\mathrm{Xe}^{+2}$ and $\mathrm{Xe}^{+3}$ was measured as a function of propellant utilization to support performance and lifetime predictions for an extended throttle table. The angular dependence of $j_{b}$ was measured at intermediate and far-field distances to assist with plume modeling and to evaluate the thrust loss due to beam divergence. Thrust correction factors were derived from the total doubles-to-singles current ratio and from the far-field divergence data.

15. SUBJECT TERMS

Ion thruster; Ion engine

\begin{tabular}{|c|c|c|c|c|c|}
\hline \multicolumn{3}{|c|}{ 16. SECURITY CLASSIFICATION OF: } & \multirow{2}{*}{$\begin{array}{l}\text { 17. LIMITATION OF } \\
\text { ABSTRACT } \\
\text { UU }\end{array}$} & \multirow{2}{*}{$\begin{array}{l}\text { 18. NUMBER } \\
\text { OF } \\
\text { PAGES } \\
29\end{array}$} & \multirow{2}{*}{$\begin{array}{l}\text { 19a. NAME OF RESPONSIBLE PERSON } \\
\text { STI Help Desk (email:help@sti.nasa.gov) } \\
\text { 19b. TELEPHONE NUMBER (include area code) } \\
\text { 443-757-5802 }\end{array}$} \\
\hline $\begin{array}{l}\text { a. REPORT } \\
U\end{array}$ & $\begin{array}{l}\text { b. ABSTRACT } \\
\mathrm{U}\end{array}$ & $\begin{array}{l}\text { c. THIS } \\
\text { PAGE } \\
\text { U }\end{array}$ & & & \\
\hline
\end{tabular}



